\title{
Structural-Based Optimizations of the Marine-Originated Meridianin C as Glucose Uptake Agents by Inhibiting GSK-3 $\beta$
}

\author{
Shuwen Han ${ }^{1,2}$, Chunlin Zhuang ${ }^{2,3} \mathbb{1}$, Wei Zhou ${ }^{4, *}$ and Fener Chen ${ }^{1,2,3, *}$ \\ 1 Institutes of Biomedical Sciences, Fudan University, Shanghai 200433, China; a8986330@163.com \\ 2 Shanghai Engineering Center of Industrial Asymmetric Catalysis for Chiral Drugs, Shanghai 200433, China; \\ zclnathan@163.com \\ 3 Engineering Center of Catalysis and Synthesis for Chiral Molecules, Department of Chemistry, \\ Fudan University, Shanghai 200433, China \\ 4 Department of Chemistry, Fudan University, Shanghai 200438, China \\ * Correspondence: zhouw@fudan.edu.cn (W.Z.); rfchen@fudan.edu.cn (F.C.)
}

Citation: Han, S.; Zhuang, C.; Zhou,

W.; Chen, F. Structural-Based

Optimizations of the Marine-

Originated Meridianin C as Glucose

Uptake Agents by Inhibiting GSK-3 $\beta$.

Mar. Drugs 2021, 19, 149. https://

doi.org/10.3390/md19030149

Academic Editor: Bill J. Baker

Received: 18 January 2021

Accepted: 9 March 2021

Published: 12 March 2021

Publisher's Note: MDPI stays neutral with regard to jurisdictional claims in published maps and institutional affiliations.

Copyright: (c) 2021 by the authors. Licensee MDPI, Basel, Switzerland. This article is an open access article distributed under the terms and conditions of the Creative Commons Attribution (CC BY) license (https:// creativecommons.org/licenses/by/ $4.0 /)$.

\begin{abstract}
Glycogen synthase kinase $3 \beta$ (GSK-3 $\beta$ ) is a widely investigated molecular target for numerous diseases, and inhibition of GSK-3 $\beta$ activity has become an attractive approach for the treatment of diabetes. Meridianin $\mathrm{C}$, an indole-based natural product isolated from marine Aplidium meridianum, has been reported as a potent GSK-3 $\beta$ inhibitor. In the present study, applying the structural-based optimization strategy, the pyrimidine group of meridianin $C$ was modified by introducing different substituents based on the 2-aminopyrimidines-substituted pyrazolo pyridazine scaffold. Among them, compounds B29 and B30 showed a much higher glucose uptake than meridianin $C(<5 \%)$ and the positive compound 4-benzyl-2-methyl-1,2,4-thiadiazolidine-3,5-dione (TDZD-8, 16\%), with no significant toxicity against HepG2 cells at the same time. Furthermore, they displayed good GSK-3 $\beta$ inhibitory activities $\left(\mathrm{IC}_{50}=5.85 ; 24.4 \mu \mathrm{M}\right)$. These results suggest that these meridianin $C$ analogues represent novel lead compounds with therapeutic potential for diabetes.
\end{abstract}

Keywords: glycogen synthase kinase $3 \beta$; inhibitor; structural-based optimization; diabetes; glucose uptake

\section{Introduction}

Diabetes is a chronic metabolic disease characterized by elevated levels of blood glucose, which leads to serious damage to the heart, blood vessels, eyes, kidneys, and nerves [1]. The International Diabetes Foundation (IDF) confirms that diabetes is one of the fastest growing global health emergencies in the 21st century. In 2019, it was estimated that 463 million people had diabetes, which is predicted to increase to 578 million by 2030 and 700 million by 2045 [2]. The major contemporary conventional oral antihyperglycemic agents include biguanides (metformin), second- and third-generation sulfonylureas, $\alpha$-glucosidase inhibitors, thiazolidinediones, dipeptidyl peptidase- 4 inhibitors, sodium-glucose co-transporter 2 inhibitors, and glucagon-like peptide-1 receptor agonists [3]. These agents are either administered as monotherapy or given in combination with other agents to achieve hypoglycemic effects [4]. Along with solubility and permeability problems, lack of target specificity, low therapeutic efficacy, severe hypoglycemia, and weight gain are the major drawbacks associated with the above-mentioned conventional drugs [5]. Thus, there is still an urgent need for new and better antihyperglycemic agents or therapeutics to reduce both the morbidity and mortality caused by diabetes mellitus.

Glycogen synthase kinase $3 \beta$ (GSK-3 $\beta$ ) is an intermediate multifunctional serine/ threonine kinase having diverse physiological pathways $[6,7]$ and involved in numerous diseases, like diabetes, inflammation, cancer, Alzheimer's disease, and bipolar disorder [8-10]. Furthermore, GSK-3 $\beta$ functionalized as the regulator of glycogen synthase (GCS), the rate-determining enzyme for glycogen synthesis, might regulate glycogen 
metabolism [11,12]. Glycogen homeostasis relies on a balance between glycogenesis and glycogenolysis. Phosphorylation of GCS by GSK-3 $\beta$ results in its deactivation, which causes an increase in blood glucose and then obviously reduces the glycogen storage of hepatocytes in type 2 diabetes [13]. The inhibition of GSK-3 $\beta$ activity leads to the activation of glycogen synthase activity and may enhance glucose uptake [14]. Therefore, the inhibition of GSK-3 $\beta$ might provide an important and alternative therapeutic strategy for the treatment of diabetes.

A number of GSK-3 $\beta$ inhibitors have been reported (Figure 1), including synthetic paullones, thiadiazolidinediones (TDZDs), and natural-origin-derived small molecules [15]. However, the majority of these compounds are considered to be toolkit compounds and do not have the necessary absorption, distribution, metabolism, excretion, and toxicity (ADMET) properties to be advanced as drug candidates into the clinic [16]. Meridianin $\mathrm{C}$ is a brominated 3-(2-aminopyrimidine)-indole compound that was initially isolated from Aplidium meridianum, an ascidian from the South Georgia Islands, by Palermo and co-workers in 1998 [8,17,18]. Meridianin C was found to be a good inhibitor of GSK-3 $\beta$ and indicated a good antitumor activity $[8,19]$. However, the activity of meridianin $C$ and its derivatives in glucose metabolism has not been disclosed yet. In the present study, we focused on structural optimizations based on meridianin $C$ in order to obtain analogues with kinase inhibitory activity and antihyperglycemic activity.<smiles>[R]c1ccc2[nH]c3c(c2c1)CC(=O)Nc1ccccc1-3</smiles><smiles>Nc1nccc(-c2c[nH]c3ccc(Br)cc23)n1</smiles>

Meridianin C

Figure 1. Chemical structures of the representative small-molecule glycogen synthase kinase $3 \beta$ (GSK-3 $\beta$ ) inhibitors.

It has been reported that the 2-aminopyrimidine-substituted pyrazolo[1,5-b] pyridazine compound (Figure 2), developed by Tavares's group, possesses excellent inhibitory activity against GSK-3 $\beta$ [11]. Consistent with the previous publication [11], the predicted binding mode of the compound with GSK-3 $\beta$ was reproduced as shown in Figure $2 a$. Similarly, we generated the docking model of meridianin $C$ with the ATP-binding site of GSK-3 $\beta$ (Figure 2b). The NH and the adjacent nitrogen in the pyrimidine ring of these two compounds (highlighted in blue) have similar hydrogen-bonding interactions with the Val135 of GSK-3 $\beta$. The aniline of the pyrazolo[1,5-b] pyridazine is located in the front solvent-exposed binding site, which has not been occupied in the meridianin $\mathrm{C}$ model. In addition, the back pocket formed by the residue Leu132 appears to be another pocket for optimization.

Thus, based on the chemical structure of meridianin $C$ and the predicted binding mode with GSK-3 $\beta$, modifications (highlighted arrows in red) at the amino group (2'-position and $5^{\prime}$-position) are proposed according to important substitutions of the pyrazolo[1,5-b] pyridazine scaffold. 


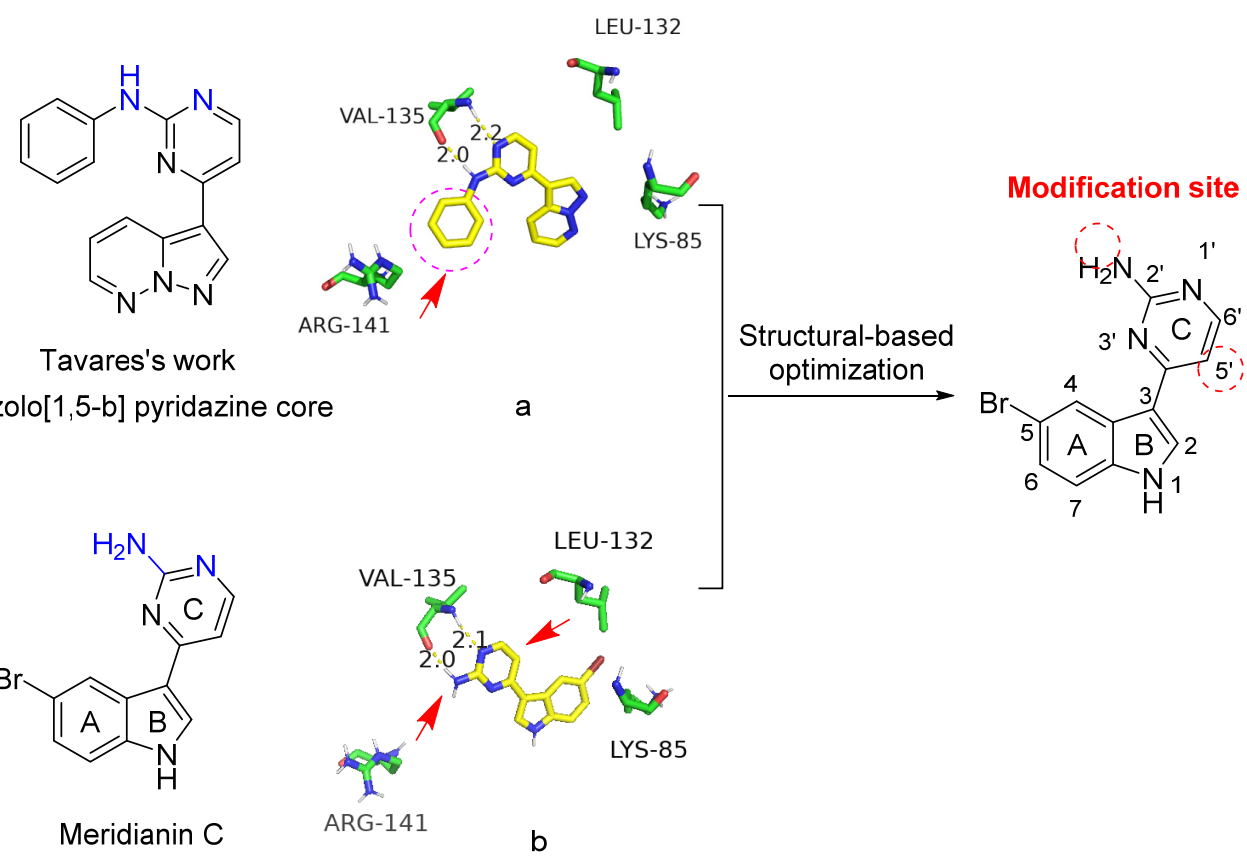

Figure 2. Predicted binding modes of pyrazolo[1,5-b] pyridazine (a) and meridianin C (b) with GSK$3 \beta$ and the structural-based optimization strategy of meridianin C (PDB code: 6B8J). The hydrogen bonds are shown by the yellow dashed lines.

\section{Results and Discussion}

\subsection{Chemistry}

The synthetic route of the target compounds A1-29 is shown in Scheme 1. The commercially available starting material 5-bromoindole $\mathbf{1}$ was acetylated using acetyl chloride and $\mathrm{SnCl}_{4}$ in toluene to give the intermediate 2 . Then, protection of indole was performed by reaction with tosyl chloride $(\mathrm{TsCl})$ in the presence of 4-(dimethylamino)pyridine (DMAP) and $N, N$-diisopropylethylamine (DIPEA) in methylene chloride, leading to the formation of compound 3 . The reaction of compound 3 with $N, N$-dimethylformamide diethyl acetal (DMF-DMA) in $N, N$-dimethylformamide (DMF) provided enaminone 4 in a $52 \%$ yield. Treatment of enaminone 4 with guanidine hydrochloride in 2-methoxyethanol and potassium carbonate led to the formation of meridianin $C 5$ in a $51 \%$ yield. Meridianin C 5 was then iodinated with $N$-iodosuccinimide (NIS) in methylene chloride to give the corresponding compound 6 in an $87 \%$ yield. Suzuki cross coupling was then performed using boronate, a (1,1'-bis (diphenylphosphino) ferrocene) dichloropalladium (II) complex with dichloromethane, and sodium carbonate in an $\mathrm{H}_{2} \mathrm{O} / \mathrm{DME}$ medium, which led to compound 8 in a $43 \%$ isolated yield. The target compounds A1-29 were obtained from the reaction of compound $\mathbf{8}$ with commercially available substituted acyl halides.

The synthetic route of the target compounds B1-31 is shown in Scheme 2. Compound 10 was obtained in a 63\% yield using 5-bromoindole 1 and 2,4-dichloropyrimidine 11. Target compounds B1-31 were obtained from the reaction of $\mathbf{1 0}$ with commercially available substituted aromatic amines. 
<smiles>CC(=O)c1c[nH]c2ccc(Br)cc12</smiles>

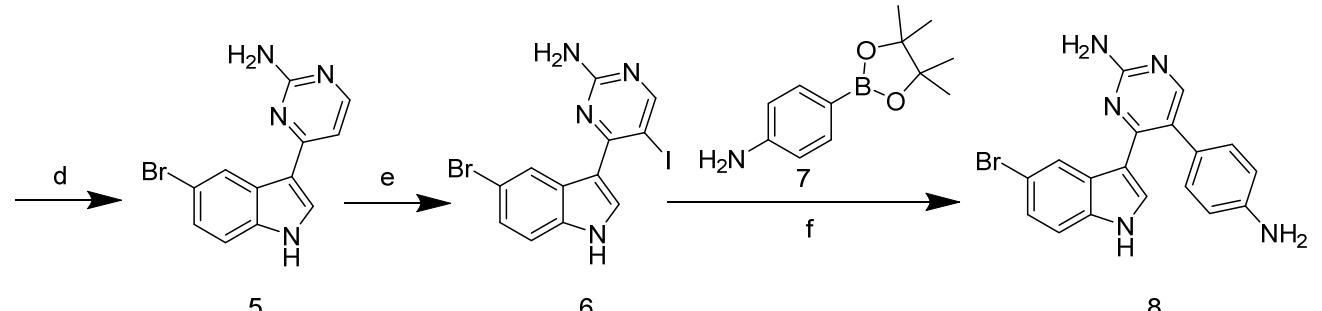

5

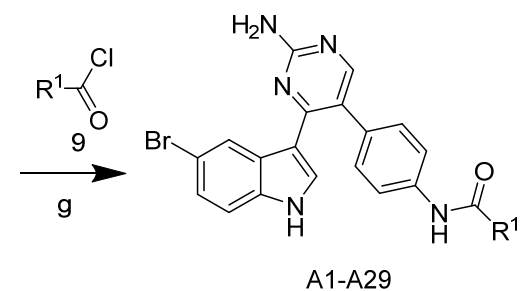

Scheme 1. Synthetic route of the compounds A1-29. Reagents and conditions: (a) $\mathrm{AcCl}, \mathrm{SnCl}_{4}$, toluene, $0{ }^{\circ} \mathrm{C}, 2 \mathrm{~h}, 87 \%$; (b) TsCl, N,N-diisopropylethylamine (DIPEA), 4-(dimethylamino)-pyridine (DMAP), DCM, room temperature (rt), $20 \mathrm{~h}, 70 \%$; (c) $N, N$-dimethylformamide diethyl acetal (DMFDMA), DMF, $110{ }^{\circ} \mathrm{C}, 4 \mathrm{~h}, 52 \%$; (d) guanidine- $\mathrm{HCl}$, 2-methoxyethanol, $\mathrm{K}_{2} \mathrm{CO}_{3}$, reflux, $24 \mathrm{~h}, 51 \%$; (e) $\mathrm{N}$-iodosuccinimide (NIS), DMF, rt, $2 \mathrm{~h}, 87 \%$; (f) $\mathrm{Pd}$ (dppf) $\mathrm{Cl}_{2} \mathrm{CH}_{2} \mathrm{Cl}_{2}, \mathrm{Na}_{2} \mathrm{CO}_{3}, \mathrm{DME}, \mathrm{H}_{2} \mathrm{O}, 85^{\circ} \mathrm{C}$, $43 \%$; (g) $\mathrm{RCOCl}$, pyridine, $0{ }^{\circ} \mathrm{C}-\mathrm{rt}, 15-51 \%$.

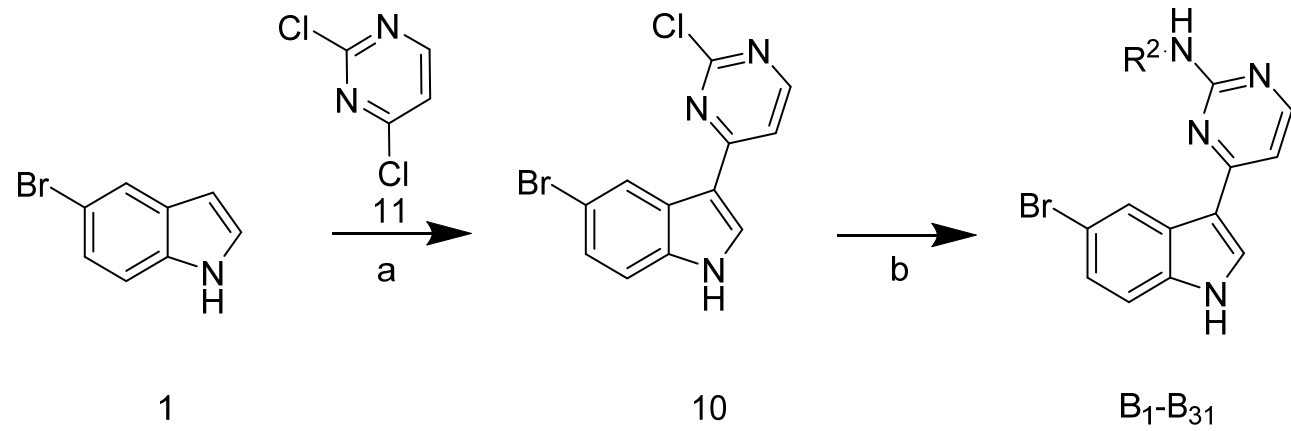

Scheme 2. Synthetic route of the compounds B1-31. Reagents and conditions: (a) $\mathrm{AlCl}_{3}, \mathrm{DCE}, 85^{\circ} \mathrm{C}$, $3 \mathrm{~h}, 63 \%$; (b) substituted aromatic amine, tosic acid, 2-pentanol, $125{ }^{\circ} \mathrm{C}, 25-63 \%$.

\subsection{Biological Activity}

Regulatory control of glycogen synthase (GCS), the final enzyme in glycogen biosynthesis, is an obvious target for antihyperglycemic control. Overexpression/overactivation of GSK-3 $\beta$ can inhibit the activation of GCS effectively, and pharmacological inhibitors of GSK-3 $\beta$ have been demonstrated to activate glycogen synthase and improve glycogen synthesis, suppress gluconeogenesis, and increase glucose uptake (Figure 3) [12,14,15]. 


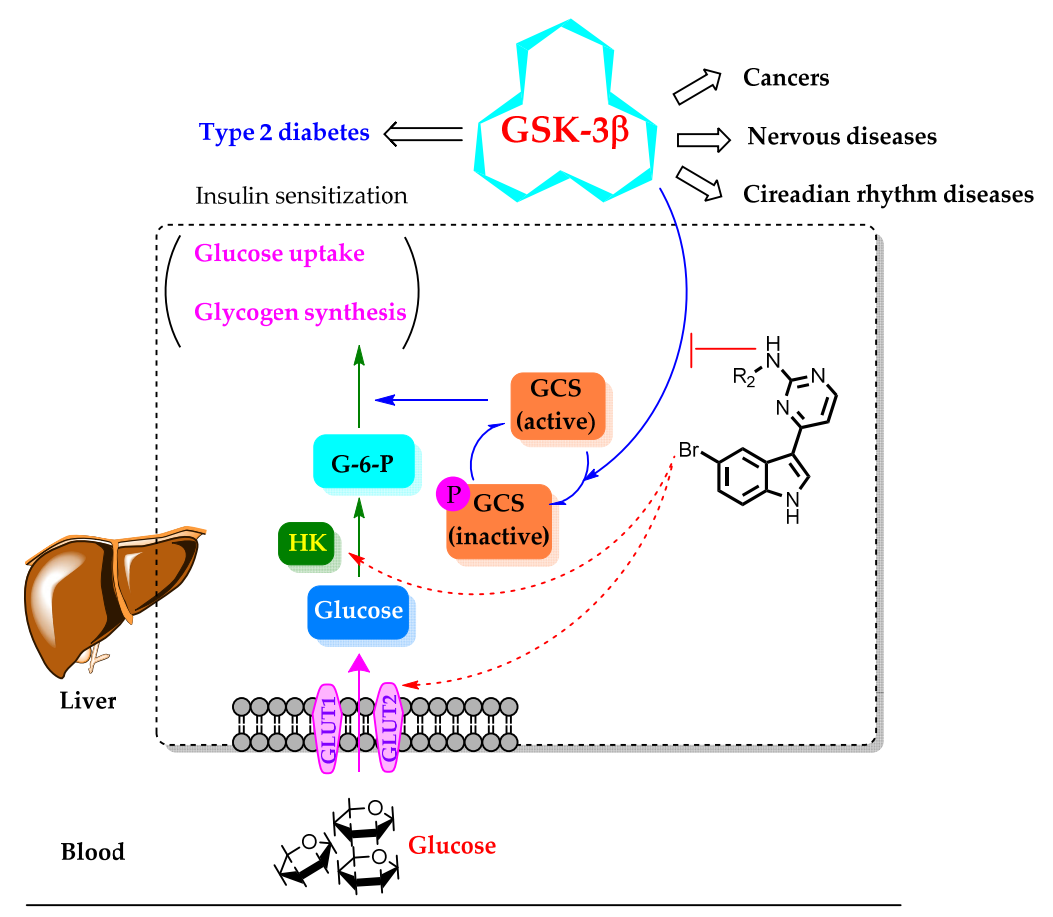

Figure 3. GSK-3 $\beta$-mediated multicellular responses and the hypothetic mechanism of the compounds in this study for glucose uptake improvement. G-6-P, glucose 6-phosphate; GCS, glycogen synthase; $\mathrm{HK}$, hexokinase.

Meridianin $\mathrm{C}$ is a marine alkaloid characterized by an indole ring connected to a pyrimidine at the three position and has extensive biological activity in GSK-3 $\beta$ inhibition. Anticancer [19] and antimalarial [20] GSK-3 $\beta$-inhibition-related activities of meridianin C were also investigated. However, to the best of our knowledge, antihyperglycemic activity of meridianin $\mathrm{C}$ and its derivatives has not been disclosed yet. Thus, we hypothesized that meridianin $C$ might influence other upstream proteins at the same time, which leads to insipid activity in glucose uptake. Nevertheless, GSK-3 $\beta$ has a close association with glucose uptake, and meridianin $C$ was confirmed to be a good inhibitor of GSK-3 $\beta$. Thus, we selected meridianin $C$ as the lead compound for modification to obtain better derivatives for diabetic therapy.

Considering that there are still several key upstream signaling proteins that would influence glucose uptake in the body, such as glucose transporters (GLUT), glycogen synthase (GCS), and glycogen phosphorylase (GP) (Figure 3), in this study, we set up a cell model of glucose uptake in HepG2 cells, instead of a GSK-3 $\beta$ assay, to screen active compounds and investigate the structure-activity relationship in order to evaluate the glucose uptake improving activity more accurately.

Herein, viabilities of the target-compound-treated HepG2 cells were first detected to exclude the influence of cell toxicity on the determination of glucose uptake using an MTT assay. As illustrated in Tables 1 and 2, most of the tested compounds showed concentration dependence after $48 \mathrm{~h}$ of incubation and $\mathrm{CC}_{50}$ values were shown to be higher than $5 \mu \mathrm{M}$, as seen in Tables 1 and 2. Comparatively, compounds with $5^{\prime}$-substitutions (series A), overall, had higher cytotoxicity than those with 2 '-substitutions (series B). According to previous reports [21], compounds without apparent cytotoxicity at $5 \mu \mathrm{M}$ were selected for investigation of their cell glucose uptake effects in the following study. 
Table 1. Chemical structures of compounds A1-29 and their relative glucose uptake and cytotoxicity in a HepG2 cell model.

Compounds $\quad \mathrm{R}^{1} \quad \begin{aligned} & \text { Cell Glucose } \\ & \text { Uptake (\%) }\end{aligned}{ }^{a} \quad \begin{gathered}\text { Cytotoxicity } \\ \left(\mathrm{CC}_{50}, \mu \mathrm{M}\right)\end{gathered}$ Compounds

A1-A29

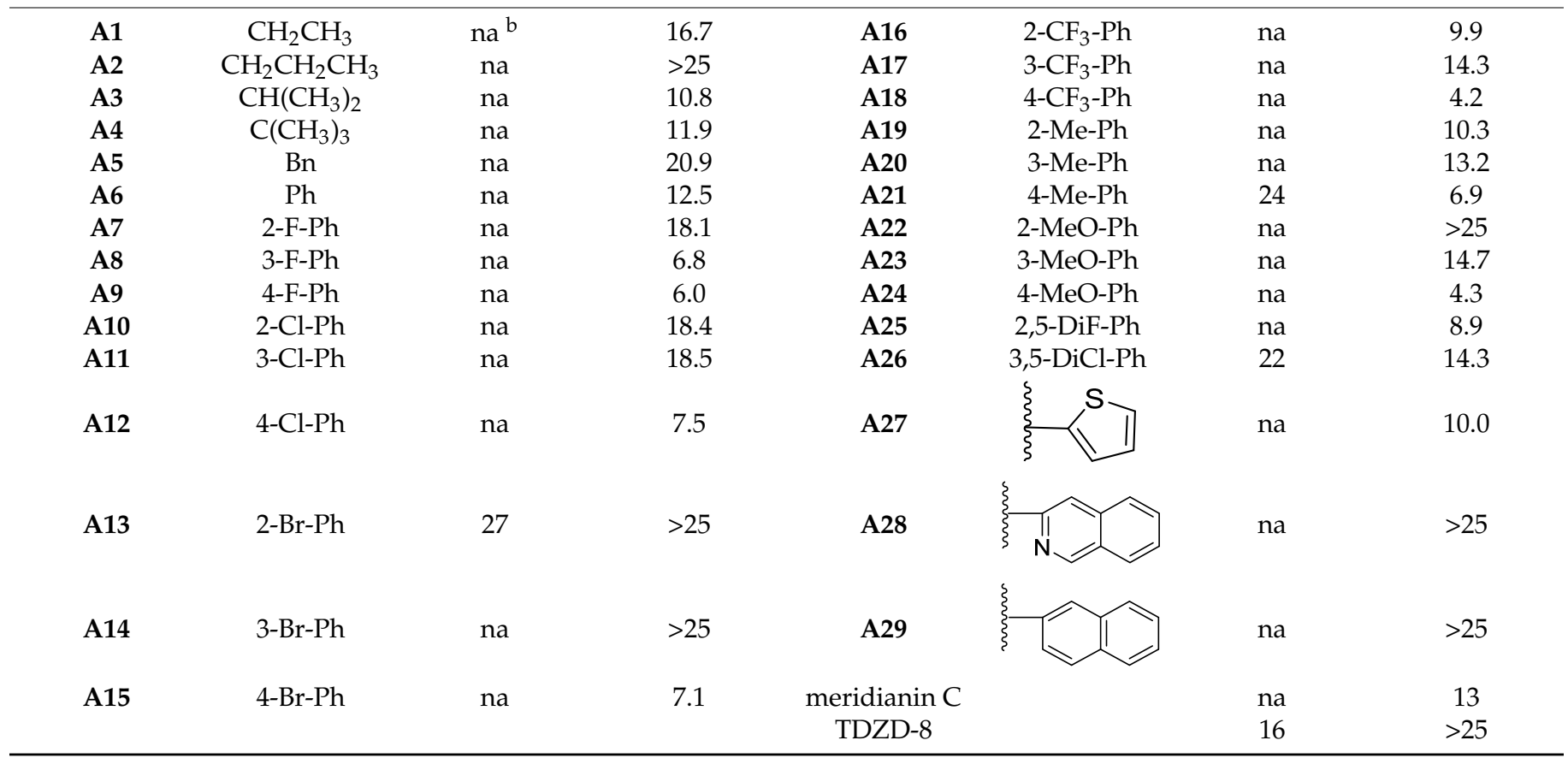

a The relative glucose uptake (\%) was calculated at $5 \mu \mathrm{M}$ compared with the original glucose concentration of the culture medium before drug administration. ${ }^{\mathrm{b}}$ na $=$ not active at $5 \mu \mathrm{M}$.

Next, the synthesized meridianin derivatives were evaluated on the basis of their ability to increase glucose transport using HepG2 as the tool cell model to test their possible anti-diabetes effect. As shown in Table 1, most of the derivatives with $5^{\prime}$-substitutions exhibited no obvious effect on the cell glucose uptake at $5 \mu \mathrm{M}$, which is similar to or better than that of meridianin $\mathrm{C}\left(\mathrm{CC}_{50}=13 \mu \mathrm{M}\right)$. However, compound $\mathbf{A 1 3}$ with an ortho-bromophenyl substitution exhibited a glucose uptake ability of $27 \%$, which was different from that of the parent meridianin $C$ and better than that of the reference compound TDZD-8 (16\%). Compound A21 with para-methylphenyl and compound A26 with 3,5-dichlorophenyl showed glucose uptake of $24 \%$ and $22 \%$, respectively.

As shown in Table 2, the derivatives with substitutions on 2'-position of the pyrimidine ring had significant improvement in terms of the relative hepatocyte glucose uptake. Overall, in this series, introducing substituents at the ortho-position of the phenyl ring improved the glucose uptake more than the presence of substituents at the para-position and the meta-position. For instance, compound B1 with 2-fluorophenyl showed a $20 \%$ glucose uptake, while compound B3 with 4-fluorophenyl showed a $7.4 \%$ uptake and compound B2 with 3-fluorophenyl showed no change at the same concentration. This phenomenon was also observed in the halogen and alkyl mono-substituted analogues (B122). At the ortho-position, the activity was along the following sequence: bromo $>$ chloro $>$ 
trifluoromethyl $>$ fluorine $>$ methoxy $>$ methyl $>$ isopropyl. Among the halogen-substituted compounds, compound B7 with a 2-bromo group showed the best glucose uptake, of $26 \%$ at $5 \mu \mathrm{M}$. For the di-substituted analogues, they all showed no apparent improvement in glucose uptake, with three exceptions. The 2,6-difluorophenyl compound B29 and the 2,6-dimethyl compound B30 showed excellent hepatocyte glucose uptake activity (29\% and 38\%, respectively), with no significant toxicity against HepG2 cells. Compound B31 with 2,6-dimethoxyl showed a $16 \%$ uptake.

Table 2. Chemical structures of compounds B1-31 and their relative glucose uptake and cytotoxicity in a HepG2 cell model.

\begin{tabular}{|c|c|c|c|c|c|c|c|}
\hline Compounds & $\mathbf{R}^{2}$ & 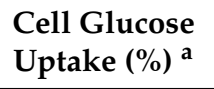 & $\begin{array}{l}\text { Cytotoxicity } \\
\left(\mathrm{CC}_{50}, \mu \mathrm{M}\right)\end{array}$ & Compounds & $\mathbf{R}^{2}$ & 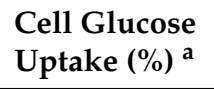 & $\begin{array}{l}\text { Cytotoxicity } \\
\left(\mathrm{CC}_{50}, \mu \mathrm{M}\right)\end{array}$ \\
\hline \multicolumn{8}{|c|}{ B1-B31 } \\
\hline B1 & 2-F-Ph & 20 & 10.5 & B16 & 2-MeO-Ph & 17 & 21.4 \\
\hline B2 & 3-F-Ph & na ${ }^{b}$ & 10.7 & B17 & 3-MeO-Ph & na & 10.6 \\
\hline B3 & 4-F-Ph & 7.4 & 12.8 & B18 & 4-MeO-Ph & 6.1 & 6.0 \\
\hline B4 & 2-Cl-Ph & 22 & $>25$ & B19 & 2-iPr-Ph & 13 & $>25$ \\
\hline B5 & 3-Cl-Ph & na & $>25$ & B20 & 3-iPr-Ph & na & 12.5 \\
\hline B6 & 4-Cl-Ph & 14.4 & 21.1 & B21 & 4-iPr-Ph & na & 13.0 \\
\hline B7 & $2-\mathrm{Br}-\mathrm{Ph}$ & 26 & $>25$ & B22 & $\mathrm{Ph}$ & na & 10.4 \\
\hline B8 & 3-Br-Ph & na & 18.7 & B23 & 3,5-DiF-Ph & na & 16.1 \\
\hline B9 & 4-Br-Ph & 12.6 & 20.3 & B24 & 3,5-DiCl-Ph & na & 10.5 \\
\hline B10 & $2-\mathrm{CF}_{3}-\mathrm{Ph}$ & 20.2 & $>25$ & B25 & 3,5-DiBr-Ph & na & $>25$ \\
\hline B11 & $3-\mathrm{CF}_{3}-\mathrm{Ph}$ & na & 17.6 & B26 & 3,5- $\mathrm{DiCF}_{3}-\mathrm{Ph}$ & na & 11.8 \\
\hline B12 & $4-\mathrm{CF}_{3}-\mathrm{Ph}$ & na & $>25$ & B27 & 3,5-DiMe-Ph & na & 6.0 \\
\hline B13 & 2-Me-Ph & 14.9 & $>25$ & B28 & 3,5-DiMeO-Ph & na & 10.0 \\
\hline B14 & 3-Me-Ph & na & 8.6 & B29 & 2,6-DiF-Ph & 29 & 22.4 \\
\hline B15 & 4-Me-Ph & na & 15.5 & B30 & 2,6-DiMe-Ph & 38 & 18.1 \\
\hline meridianin $C$ & & na & 13.0 & B31 & 2,6-DiMeO-Ph & 16 & 19.2 \\
\hline TDZD-8 & & 16 & $>25$ & & & & \\
\hline
\end{tabular}

a The relative glucose uptake (\%) was calculated at $5 \mu \mathrm{M}$ compared with the original glucose concentration of the culture medium before drug administration. ${ }^{\mathrm{b}}$ na $=$ not active at $5 \mu \mathrm{M}$.

To further confirm the inhibitory activities against GSK-3 $\beta$ of the synthesized meridianin derivatives, compounds with the best activity on cell glucose uptake were selected for a GSK-3 $\beta$ Kinase-Glo ${ }^{\mathrm{TM}}$ luminescent assay. As shown in Tables 1 and 3, compounds with 5'-substitutions (A13 and A26) exhibited the ability of glucose uptake but showed no apparent inhibitory activity against GSK-3 $\beta$ at $30 \mu \mathrm{M}$. On the other hand, compounds B29 and B30 showed much better potencies, with inhibitory activity $\left(\mathrm{IC}_{50}\right)$ values of 5.85 and $24.4 \mu \mathrm{M}$, respectively, which were slightly lower than that of the lead compound meridianin $\mathrm{C}\left(\mathrm{IC}_{50}=2 \mu \mathrm{M}\right.$; [18]). 
Table 3. Inhibitory activity $\left(\mathrm{IC}_{50}\right)$ against human GSK-3 $\beta$.

\begin{tabular}{cc}
\hline Compounds & IC $_{\mathbf{5 0}}(\boldsymbol{\mu M})$ GSK-3 $\beta$ \\
\hline A13 & $>30$ \\
A26 & $>30$ \\
B29 & 5.85 \\
B30 & 24.4 \\
meridianin C & $2[18]$ \\
\hline
\end{tabular}

Finally, the structural binding mode of the potent 2-aminopyrimidine-modified analogues were predicted to show compounds B29 and B30 adopting similar poses within the ATP-binding site of GSK-3 $\beta$ (Figure 4). They maintained the key interactions of meridianin $\mathrm{C}$ as shown in Figure 2. Additionally, the aniline group well occupied the front solventexposed binding site. However, no new hydrogen-bonding interactions were formed, signifying that there was no improvement in the GSK-3 $\beta$ but a significant increase in the cell glucose uptake.

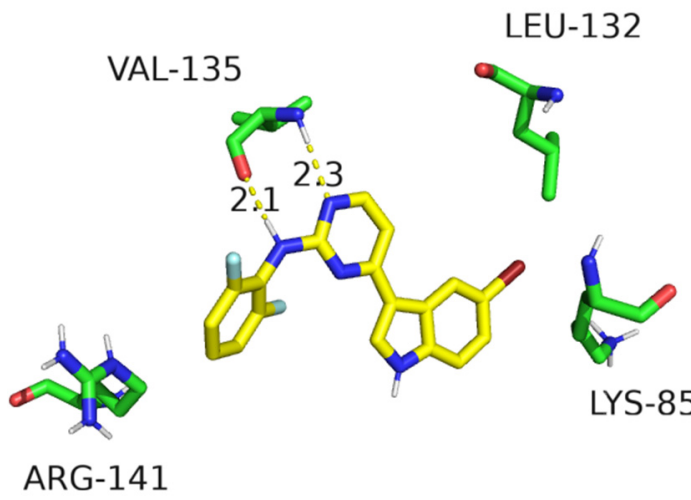

(a)

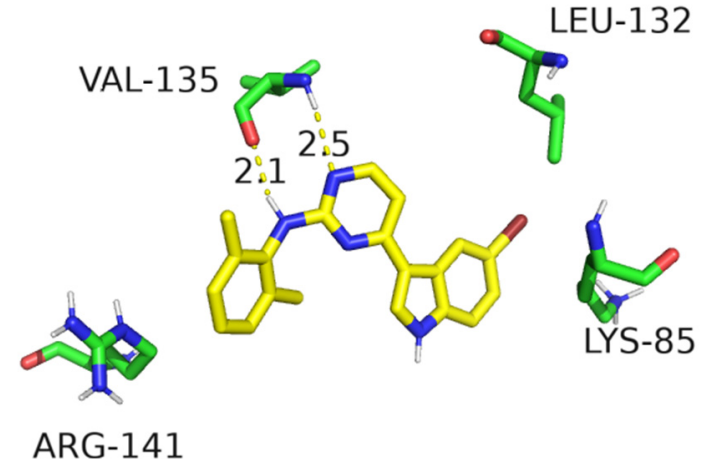

(b)

Figure 4. Binding modes of compounds B29 (a) and B30 (b) in the ATP site of GSK-3 $\beta$ (PDB code: 6B8J). The hydrogen bonds are shown by the yellow dashed lines.

Conclusively, meridianin C had better GSK-3 $\beta$ inhibition but had no glucose uptake activity, A13 and A26 showed better glucose uptake activity but without GSK-3 $\beta$ inhibition, and B29 and B30 displayed the best glucose uptake ability with moderate GSK-3 $\beta$ inhibitory activities. Therefore, from our results, there seems no close association between GSK-3 $\beta$ inhibitory activity and glucose uptake efficiency for meridianin $C$ and its analogues, which is consistent with our hypothesis that these novel compounds might interfere in the other signaling proteins (such as GLUT, HK, and GCS) at the same time to influence glucose uptake (Figure 3). The mechanisms of these active compounds need to be clarified in more detail. Anyhow, in this study, two novel hit compounds of B29 and B30 were screened and found to have proper glucose uptake improving ability, as well as a definite GSK-3 $\beta$ binding and inhibitory activity. Thus, in further studies, based on the current structures, we will optimize the structures continuously, along with the activities with other involved proteins, to obtain much better anti-diabetes drugs.

\section{Materials and Methods}

\subsection{Chemistry}

\subsubsection{General Procedure}

Chemical reagents and solvents, purchased from commercial sources, were of analytical grade and were used without further purification. All air-sensitive reactions were run under a nitrogen atmosphere. All the reactions were monitored by TLC on recoated silica gel $\mathrm{G}$ plates at $254 \mathrm{~nm}$ under a UV lamp using ethyl acetate/n-hexane as the eluent. Column 
chromatography was performed on a glass column packed with silica gel (200-300 mesh) using ethyl acetate/n-hexane as the eluent. Melting points were measured on an SGW $\mathrm{X}-1$ microscopic melting point apparatus. Proton nuclear magnetic resonance $\left({ }^{1} \mathrm{H}\right.$ NMR) and carbon nuclear magnetic resonance $\left({ }^{13} \mathrm{C}\right.$ NMR) spectra were recorded in DMSO- $d_{6}$, $\mathrm{CD}_{3} \mathrm{OD}$, or $\mathrm{CDCl}_{3}$ on a Bruker $\mathrm{AV} 400 \mathrm{MHz}$ spectrometer. Chemical shifts were reported in $\delta(\mathrm{ppm})$ units relative to the internal standard tetramethylsilane (TMS). Mass spectra and HRMS were obtained on a Waters Quattro Micromass instrument and a Bruker Compact instrument, respectively, using electrospray ionization (ESI) techniques. The purities of the target compounds were $\geq 95 \%$, measured by HPLC, performed on an Agilent 1260 HPLC system with a UV detector and an Agilent Eclipse Plus C18 column $(150 \times 4.6 \mathrm{~mm}, 5 \mu \mathrm{m})$, eluting with a mixture of solvents acetonitrile and water. (a) 0-12 $\mathrm{min}, 50-95 \% \mathrm{ACN}$; (b) 12-16 $\mathrm{min}, 95 \%$ ACN; (c) 16-16.01 min, 95-50\% ACN; (d) $16.01-20 \mathrm{~min}, 50 \%$ ACN. Peaks were detected at $\lambda 254 \mathrm{~nm}$ with a flow rate of $1.0 \mathrm{~mL} / \mathrm{min}$. The final structures were fully characterized by ${ }^{1} \mathrm{H}$ NMR, ${ }^{13} \mathrm{C}$ NMR and HRMS (see Supplementary Materials).

\subsubsection{Synthesis of 1-(5-Bromo- $1 H$-indol-3-yl) Ethanone 2}

To a solution of 5-bromoindole $\mathbf{1}(5.00 \mathrm{~g}, 25.5 \mathrm{mmol}, 1.00 \mathrm{eq})$ in $25 \mathrm{~mL}$ of anhydrous toluene was added $(4.00 \mathrm{~g}, 51.0 \mathrm{mmol}, 2.00 \mathrm{eq})$ acetyl chloride at $0{ }^{\circ} \mathrm{C}$. The resulting mixture was stirred for $15 \mathrm{~min}$ at $0{ }^{\circ} \mathrm{C}$, and a solution of $\mathrm{SnCl}_{4}(13.3 \mathrm{~g}, 51.0 \mathrm{mmol}, 2.00 \mathrm{eq})$ in $24 \mathrm{~mL}$ anhydrous toluene was added. The resulting solution was stirred for $2 \mathrm{~h}$ at $0{ }^{\circ} \mathrm{C}$, and $75 \mathrm{~mL}$ of $8 \% \mathrm{NaHCO}_{3}$ was added dropwise. The resulting slurry was diluted with $150 \mathrm{~mL}$ of ethyl acetate, dried $\left(\mathrm{Na}_{2} \mathrm{SO}_{4}\right)$, and filtered. The solvent was removed with a rotary evaporator. The crude product was purified by column chromatography to afford the compound 2 . Yield: $87 \%$, brick red solid, mp $250.4-251.3{ }^{\circ} \mathrm{C} .{ }^{1} \mathrm{H}$ NMR $\left(400 \mathrm{MHz}, \mathrm{CD}_{3} \mathrm{OD}\right) \delta 8.38(\mathrm{~d}$, $J=2.0 \mathrm{~Hz}, 1 \mathrm{H}), 8.17(\mathrm{~s}, 1 \mathrm{H}), 7.45-7.23(\mathrm{~m}, 2 \mathrm{H}), 2.51(\mathrm{~s}, 3 \mathrm{H})$.

\subsubsection{Synthesis of 1-(5-Bromo-1-tosyl-1H-indol-3-yl) Ethanone 3}

To the solution of 5-bromo-3-acetyl indole $2(5.00 \mathrm{~g}, 21.0 \mathrm{mmol}, 1.00 \mathrm{eq})$ in dichloromethane was added DMAP $(0.128 \mathrm{~g}, 1.05 \mathrm{mmol}, 0.0500 \mathrm{eq}), p$-toluenesulfonyl choride ( $\mathrm{TsCl}, 4.40 \mathrm{~g}$, $23.1 \mathrm{mmol}, 1.10 \mathrm{eq}$ ), and $\mathrm{N}, \mathrm{N}$-diisopropylethylamine (DIPEA, $4.07 \mathrm{~g}, 31.5 \mathrm{mmol}, 1.50 \mathrm{eq}$ ). The mixture was stirred at room temperature for $20 \mathrm{~h}$. The reaction was then quenched by the addition of $10 \% \mathrm{HCl}$. Dichloromethane was added to the reaction mixture. The organic layer was separated, dried over anhydrous sodium sulphate, and concentrated to get a crude compound. The crude product was purified by column chromatography to afford the compound 3. Yield: $70 \%$, white solid, $\mathrm{mp} 140.6-141.5{ }^{\circ} \mathrm{C} .{ }^{1} \mathrm{H} \mathrm{NMR}\left(400 \mathrm{MHz}, \mathrm{CDCl}_{3}\right) \delta$ $8.47(\mathrm{~d}, J=2.0 \mathrm{~Hz}, 1 \mathrm{H}), 8.15(\mathrm{~s}, 1 \mathrm{H}), 7.79(\mathrm{~s}, 1 \mathrm{H}), 7.76(\mathrm{~d}, J=7.3 \mathrm{~Hz}, 2 \mathrm{H}), 7.44(\mathrm{~d}, J=8.9 \mathrm{~Hz}$, $1 \mathrm{H}), 7.27(\mathrm{~d}, J=8.1 \mathrm{~Hz}, 2 \mathrm{H}), 2.53(\mathrm{~s}, 3 \mathrm{H}), 2.36(\mathrm{~s}, 3 \mathrm{H})$.

\subsubsection{Synthesis of 1-(5-Bromo-1-tosyl-1H-indol-3-yl)-3-(dimethylamino) prop-2-en-1-one 4}

1-(5-bromo-1-tosyl-1H-indol-3-yl) ethanone 3 ( $4.00 \mathrm{~g}, 10.2 \mathrm{mmol}, 1.00 \mathrm{eq}$ ) was taken in anhydrous $\mathrm{N}, \mathrm{N}$-dimethylformamide (DMF, $40 \mathrm{~mL}$ ), and a solution of dimethyl formamidedimethylacetal (DMF-DMA, $1.82 \mathrm{~g}, 15.3 \mathrm{mmol}, 1.50 \mathrm{eq}$ ) was added to the same solvent $(4 \mathrm{~mL})$. The resultant solution was heated at $110^{\circ} \mathrm{C}$ for $4 \mathrm{~h}$ under a $\mathrm{N}_{2}$ atmosphere. After cooling, the solution was poured into water and then extracted with ethyl acetate. The combined organic layers were dried over anhydrous sodium sulphate and concentrated to dryness under reduced pressure. The crude product was purified by column chromatography to afford the compound 4. Yield: $52 \%$, pale yellow solid, $\mathrm{mp} 176.7-178.5^{\circ} \mathrm{C} .{ }^{1} \mathrm{H}$ NMR $\left(400 \mathrm{MHz}, \mathrm{CDCl}_{3}\right) \delta 8.44(\mathrm{~s}, 1 \mathrm{H}), 7.96(\mathrm{~s}, 1 \mathrm{H}), 7.73-7.64(\mathrm{~m}, 4 \mathrm{H}), 7.37-7.29(\mathrm{~m}, 1 \mathrm{H}), 7.16(\mathrm{~d}$, $J=8.1 \mathrm{~Hz}, 2 \mathrm{H}), 5.46(\mathrm{~d}, J=12.3 \mathrm{~Hz}, 1 \mathrm{H}), 3.07(\mathrm{~s}, 3 \mathrm{H}), 2.87(\mathrm{~s}, 3 \mathrm{H}), 2.27(\mathrm{~s}, 3 \mathrm{H})$.

\subsubsection{Synthesis of Meridianin C 5}

A mixture of 1-(5-bromo-1-tosyl-1H-indol-3-yl)-3-(dimethylamino) prop-2-en-1-one 4 $(2.00 \mathrm{~g}, 4.47 \mathrm{mmol}, 1.00 \mathrm{eq})$, guanidine hydrochloride $(0.64 \mathrm{~g}, 6.71 \mathrm{mmol}, 1.50 \mathrm{eq})$, anhydrous $\mathrm{K}_{2} \mathrm{CO}_{3}(1.24 \mathrm{~g}, 8.94 \mathrm{mmol}, 2.00 \mathrm{eq})$, and 2-methoxyethanol $(20 \mathrm{~mL})$ was heated at reflux 
temperature for $24 \mathrm{~h}$ under a $\mathrm{N}_{2}$ atmosphere. After cooling, the solution was poured into water and then extracted with ethyl acetate. The combined organic layers were dried over anhydrous sodium sulphate and concentrated to dryness under reduced pressure. The crude product was purified by column chromatography to afford the compound 5. Yield: $51 \%$, pale yellow solid, mp $105.4-106.3{ }^{\circ} \mathrm{C} .{ }^{1} \mathrm{H}$ NMR $\left(400 \mathrm{MHz}, \mathrm{DMSO}-d_{6}\right) \delta 11.86(\mathrm{~s}, 1 \mathrm{H})$, $8.75(\mathrm{~s}, 1 \mathrm{H}), 8.25(\mathrm{~s}, 1 \mathrm{H}), 8.11(\mathrm{~s}, 1 \mathrm{H}), 7.40(\mathrm{~d}, J=8.1 \mathrm{~Hz}, 1 \mathrm{H}), 7.29(\mathrm{~d}, J=8.8 \mathrm{~Hz}, 1 \mathrm{H}), 7.00$ (s, $1 \mathrm{H}), 6.49(\mathrm{~s}, 2 \mathrm{H})$.

\subsubsection{Synthesis of 4-(5-bromo- $1 H$-indol-3-yl)-5-iodopyrimidin-2-amine 6}

N-Iodosuccinimide (NIS, $0.490 \mathrm{~g}, 2.17 \mathrm{mmol}, 1.10 \mathrm{eq}$ ) was added to a solution of meridianin C 5 (0.570 g, $1.97 \mathrm{mmol}, 1.00 \mathrm{eq})$ in anhydrous $N, N$-dimethylformamide (DMF, $6 \mathrm{~mL}$ ). The reaction was stirred at room temperature for $1.5 \mathrm{~h}$ before concentrating to remove the solvent. The residue was partitioned between ethyl acetate $(100 \mathrm{~mL})$ and $\mathrm{Na}_{2} \mathrm{~S}_{2} \mathrm{O}_{3}(100 \mathrm{~mL})$. The organics were washed with $\mathrm{NaHCO}_{3}(80 \mathrm{~mL})$ and brine $(10 \mathrm{~mL})$, dried over anhydrous sodium sulphate, and concentrated under reduced pressure. The crude product was purified by column chromatography to afford the compound 6. Yield: $87 \%$, pale yellow solid, mp $203.5-204.3{ }^{\circ} \mathrm{C} .{ }^{1} \mathrm{H}$ NMR $\left(400 \mathrm{MHz}, \mathrm{DMSO}-d_{6}\right) \delta 11.85(\mathrm{~s}, 1 \mathrm{H})$, $8.51(\mathrm{~s}, 1 \mathrm{H}), 8.46(\mathrm{~s}, 1 \mathrm{H}), 8.39(\mathrm{~d}, J=2.0 \mathrm{~Hz}, 1 \mathrm{H}), 7.45(\mathrm{~d}, J=8.7 \mathrm{~Hz}, 1 \mathrm{H}), 7.30(\mathrm{dd}, J=8.7$, $2.1 \mathrm{~Hz}, 1 \mathrm{H}), 6.79(\mathrm{~s}, 2 \mathrm{H})$.

\subsubsection{Synthesis of 5-(4-aminophenyl)-4-(5-bromo- $1 H$-indol-3-yl) pyrimidin-2-amine 8}

A mixture of compound $6(0.500 \mathrm{~g}, 1.20 \mathrm{mmol}, 1.00 \mathrm{eq}), 4$-aminophenylboronic acid pinacol ester 7 (0.317 g, $1.45 \mathrm{mmol}, 1.20 \mathrm{eq})$, and $\mathrm{Na}_{2} \mathrm{CO}_{3}(0.319 \mathrm{~g}, 3.01 \mathrm{mmol}, 2.50 \mathrm{eq})$ under a nitrogen atmosphere was treated with DME $(9 \mathrm{~mL})$, water $(3 \mathrm{~mL})$, and Pd (dppf) $\mathrm{Cl}_{2} \mathrm{CH}_{2} \mathrm{Cl}_{2}(0.0500 \mathrm{~g}$, $0.0600 \mathrm{mmol}, 0.0500 \mathrm{eq})$. The mixture was purged with bubbling nitrogen for $2 \mathrm{~min}$ and then stirred at $85{ }^{\circ} \mathrm{C}$ for $16 \mathrm{~h}$, cooled to room temperature, and partitioned between ethyl acetate and water. The aqueous layer was extracted with ethyl acetate twice, and the combined organic layers were washed with brine, dried over anhydrous sodium sulphate, filtered, and concentrated. The crude product was purified by column chromatography to afford the compound 8. Yield: $43 \%$, pale yellow solid, $\mathrm{mp}$ 217.7-218.3 ${ }^{\circ} \mathrm{C} .{ }^{1} \mathrm{H}$ NMR $\left(400 \mathrm{MHz}, \mathrm{DMSO}-d_{6}\right) \delta 11.49(\mathrm{~s}, 1 \mathrm{H}), 8.65(\mathrm{~s}, 1 \mathrm{H}), 7.94(\mathrm{~s}, 1 \mathrm{H}), 7.32$ $(\mathrm{d}, J=8.5 \mathrm{~Hz}, 1 \mathrm{H}), 7.24(\mathrm{~d}, J=8.5 \mathrm{~Hz}, 1 \mathrm{H}), 6.89(\mathrm{~d}, J=7.9 \mathrm{~Hz}, 2 \mathrm{H}), 6.74(\mathrm{~s}, 1 \mathrm{H}), 6.61(\mathrm{~d}$, $J=8.0 \mathrm{~Hz}, 2 \mathrm{H}), 6.55(\mathrm{~s}, 2 \mathrm{H}), 5.33(\mathrm{~s}, 2 \mathrm{H}) .{ }^{13} \mathrm{C} \mathrm{NMR}\left(100 \mathrm{MHz}, \mathrm{DMSO}-d_{6}\right) \delta 161.55,160.62$, $156.92,148.17,134.70,130.90,130.22,128.23,125.40,125.19,124.80,121.82,114.52,113.68$, 113.45, 112.81. HRMS calcd for $\mathrm{C}_{18} \mathrm{H}_{15} \mathrm{BrN}_{5}{ }^{+}[\mathrm{M}+\mathrm{H}]{ }^{+} 380.0505$, found 380.0504 .

\subsubsection{Synthesis of 5-bromo-3-(2-chloropyrimidin-4-yl)- $1 H$-indole $\mathbf{1 0}$}

To the solution of 2,4-dichloropyrimidine $(3.04 \mathrm{~g}, 20.4 \mathrm{mmol}, 1.00 \mathrm{eq})$ in dichloroethane $(20 \mathrm{~mL})$ was added aluminum chloride $\left(\mathrm{AlCl}_{3}, 3.26 \mathrm{~g}, 24.5 \mathrm{mmol}, 1.20 \mathrm{eq}\right)$ under a $\mathrm{N}_{2}$ atmosphere, and the mixture was stirred for $5 \mathrm{~min}$. 5-Bromoindole 1 ( $4.00 \mathrm{~g}, 20.4 \mathrm{mmol}$, $1.00 \mathrm{eq}$ ) was added, and the mixture was heated at $85^{\circ} \mathrm{C}$ for $3 \mathrm{~h}$. After completion of the reaction, the reaction mixture was cooled at room temperature and poured into ice-cold water $(30 \mathrm{~mL})$ with continuous stirring for $20 \mathrm{~min}$. The crude products were isolated by extracting with ethyl acetate. The organic phase was separated and washed with brine, dried over sodium sulphate, and evaporated under vacuum. The crude products obtained were further purified by silica gel column chromatography using an ethyl acetate-hexane mixture. Yield: $63 \%$, pale yellow solid, mp $260.5-261.3{ }^{\circ} \mathrm{C}$. ${ }^{1} \mathrm{H}$ NMR (400 MHz, DMSO- $\left.d_{6}\right)$ $\delta 12.25(\mathrm{~s}, 1 \mathrm{H}), 8.57(\mathrm{~d}, J=2.6 \mathrm{~Hz}, 2 \mathrm{H}), 8.55(\mathrm{~d}, J=5.6 \mathrm{~Hz}, 1 \mathrm{H}), 7.92(\mathrm{~d}, J=5.5 \mathrm{~Hz}, 1 \mathrm{H}), 7.47$ $(\mathrm{d}, J=8.7 \mathrm{~Hz}, 1 \mathrm{H}), 7.36(\mathrm{dd}, J=8.6,1.9 \mathrm{~Hz}, 1 \mathrm{H})$.

\section{General Procedure for the Preparation of the Final Compounds A1-29}

To a solution of 5-(4-aminophenyl)-4-(5-bromo-1H-indol-3-yl) pyrimidin-2-amine 8 (200 mg, $0.530 \mathrm{mmol}, 1.00 \mathrm{eq})$ in pyridine $(5 \mathrm{~mL})$, the appropriate substituted benzoyl chloride derivative $(0.680 \mathrm{mmol}, 1.30 \mathrm{eq})$ was added and the mixture stirred for $1 \mathrm{~h}$. The so- 
lution was poured into ice-cold water and then extracted with ethyl acetate. The combined organic layers were dried over anhydrous sodium sulphate and concentrated to dryness under reduced pressure. The crude product was purified by column chromatography to afford the target compounds.

General Procedure for the Preparation of the Final Compounds B1-31

$p$-Toluene sulfonic acid hydrate $(203 \mathrm{mg}, 1.07 \mathrm{mmol}, 1.10 \mathrm{eq})$ was added in one portion to a mixture of substituted aromatic amine (0.972 mmol, $1.00 \mathrm{eq})$ and compound 10 (300 $\mathrm{mg}$, $0.972 \mathrm{mmol}, 1.00 \mathrm{eq})$ in 2-pentanol $(10 \mathrm{~mL})$. The resulting mixture was then stirred at 125 ${ }^{\circ} \mathrm{C}$ for $18 \mathrm{~h}$. the solution was poured into ice-cold water and then extracted with ethyl acetate. The combined organic layers were dried over anhydrous sodium sulphate and concentrated to dryness under reduced pressure. The crude product was purified by column chromatography to afford the target compounds.

3.1.9. N-(4-(2-amino-4-(5-bromo-1H-indol-3-yl) pyrimidin-5-yl) phenyl) Propionamide A1

Yield: $30 \%$, pale yellow solid, mp 193.6-194.2 ${ }^{\circ} \mathrm{C} .{ }^{1} \mathrm{H}$ NMR $\left(400 \mathrm{MHz}, \mathrm{DMSO}-d_{6}\right) \delta$ $11.36(\mathrm{~s}, 1 \mathrm{H}), 9.86(\mathrm{~s}, 1 \mathrm{H}), 8.44(\mathrm{~s}, 1 \mathrm{H}), 7.87(\mathrm{~s}, 1 \mathrm{H}), 7.50(\mathrm{~d}, J=8.2 \mathrm{~Hz}, 2 \mathrm{H}), 7.19(\mathrm{~d}, J=8.6 \mathrm{~Hz}$, $1 \mathrm{H}), 7.11(\mathrm{~d}, J=8.6 \mathrm{~Hz}, 1 \mathrm{H}), 7.05(\mathrm{~d}, J=8.1 \mathrm{~Hz}, 2 \mathrm{H}), 6.53(\mathrm{~d}, J=17.5 \mathrm{~Hz}, 3 \mathrm{H}), 2.21(\mathrm{q}$, $J=7.5 \mathrm{~Hz}, 2 \mathrm{H}), 0.96(\mathrm{t}, J=7.5 \mathrm{~Hz}, 3 \mathrm{H}) .{ }^{13} \mathrm{C}$ NMR $\left(100 \mathrm{MHz}, \mathrm{DMSO}-d_{6}\right) \delta 172.51,162.91$, 159.91, 158.66, 139.03, 134.97, 133.45, 130.61, 130.24, 128.37, 125.20, 124.99, 121.22, 119.67, $113.98,113.55,112.93,30.01,10.16$. HRMS calcd for $\mathrm{C}_{21} \mathrm{H}_{19} \mathrm{BrN}_{5} \mathrm{O}^{+}[\mathrm{M}+\mathrm{H}]{ }^{+} 436.0767$, found 437.0765 . HPLC purity $98.27 \%\left(t_{R}=10.3 \mathrm{~min}\right)$.

3.1.10. N-(4-(2-amino-4-(5-bromo-1H-indol-3-yl) pyrimidin-5-yl) phenyl) Butyramide A2

Yield: $33 \%$, pale yellow solid, mp $187.6-188.3{ }^{\circ} \mathrm{C} .{ }^{1} \mathrm{H}$ NMR $\left(400 \mathrm{MHz}, \mathrm{DMSO}-d_{6}\right) \delta$ $11.44(\mathrm{~s}, 1 \mathrm{H}), 9.94(\mathrm{~s}, 1 \mathrm{H}), 8.55(\mathrm{~s}, 1 \mathrm{H}), 7.99(\mathrm{~s}, 1 \mathrm{H}), 7.63(\mathrm{~d}, J=8.1 \mathrm{~Hz}, 2 \mathrm{H}), 7.32(\mathrm{~d}, J=8.6 \mathrm{~Hz}$, $1 \mathrm{H}), 7.23(\mathrm{~d}, J=8.1 \mathrm{~Hz}, 1 \mathrm{H}), 7.17(\mathrm{~d}, J=8.1 \mathrm{~Hz}, 2 \mathrm{H}), 6.69(\mathrm{~s}, 1 \mathrm{H}), 6.60(\mathrm{~s}, 2 \mathrm{H}), 2.30(\mathrm{t}$, $J=7.3 \mathrm{~Hz}, 2 \mathrm{H}), 1.62(\mathrm{~m}, 2 \mathrm{H}), 0.92(\mathrm{t}, J=7.3 \mathrm{~Hz}, 3 \mathrm{H}) .{ }^{13} \mathrm{C}$ NMR $\left(100 \mathrm{MHz}, \mathrm{DMSO}-d_{6}\right) \delta$ $170.76,162.02,159.01,157.80,138.08,134.09,132.63,129.72,129.34,127.49,124.30,124.10$, $120.38,118.84,113.06,112.66,112.09,37.95,18.15,13.23$. HRMS calcd for $\mathrm{C}_{22} \mathrm{H}_{21} \mathrm{BrN}_{5} \mathrm{O}^{+}[\mathrm{M}$ $+H]+450.0924$, found 450.0920. HPLC purity 95.59\% $\left(t_{R}=11.0 \mathrm{~min}\right)$.

3.1.11. N-(4-(2-amino-4-(5-bromo-1H-indol-3-yl) pyrimidin-5-yl) phenyl) Isobutyramide A3

Yield: $33 \%$, pale yellow solid, mp $172.6-173.3^{\circ} \mathrm{C} .{ }^{1} \mathrm{H}$ NMR $\left(400 \mathrm{MHz}, \mathrm{DMSO}-d_{6}\right) \delta$ $11.44(\mathrm{~s}, 1 \mathrm{H}), 9.90(\mathrm{~s}, 1 \mathrm{H}), 8.57(\mathrm{~s}, 1 \mathrm{H}), 8.00(\mathrm{~s}, 1 \mathrm{H}), 7.65(\mathrm{~d}, J=8.1 \mathrm{~Hz}, 2 \mathrm{H}), 7.33(\mathrm{~d}, J=8.6 \mathrm{~Hz}$, $1 \mathrm{H}), 7.25(\mathrm{~d}, J=6.6 \mathrm{~Hz}, 1 \mathrm{H}), 7.18(\mathrm{~d}, J=8.2 \mathrm{~Hz}, 2 \mathrm{H}), 6.71(\mathrm{~s}, 1 \mathrm{H}), 6.61(\mathrm{~s}, 2 \mathrm{H}), 2.61(\mathrm{~m}, 1 \mathrm{H})$, $1.12(\mathrm{~d}, J=6.8 \mathrm{~Hz}, 6 \mathrm{H}) .{ }^{13} \mathrm{C}$ NMR $\left(100 \mathrm{MHz}, \mathrm{DMSO}-d_{6}\right) \delta 174.83,162.03,159.01,157.81$, $138.19,134.09,132.64,129.74,129.32,127.50,124.31,124.11,120.38,118.94,113.08,112.67$, $112.08,34.54,19.11$. HRMS calcd for $\mathrm{C}_{22} \mathrm{H}_{21} \mathrm{BrN}_{5} \mathrm{O}^{+}[\mathrm{M}+\mathrm{H}]{ }^{+} 450.0924$, found 450.0917 . HPLC purity $95.64 \%\left(t_{R}=11.0 \mathrm{~min}\right)$.

3.1.12. N-(4-(2-amino-4-(5-bromo-1H-indol-3-yl) pyrimidin-5-yl) phenyl) Pivalamide A4

Yield: $35 \%$, pale yellow solid, mp $139.6-140.3{ }^{\circ} \mathrm{C} .{ }^{1} \mathrm{H}$ NMR $\left(400 \mathrm{MHz}, \mathrm{DMSO}-d_{6}\right) \delta$ $11.43(\mathrm{~s}, 1 \mathrm{H}), 9.26(\mathrm{~s}, 1 \mathrm{H}), 8.57(\mathrm{~s}, 1 \mathrm{H}), 7.97(\mathrm{~s}, 1 \mathrm{H}), 7.67(\mathrm{~d}, J=8.3 \mathrm{~Hz}, 2 \mathrm{H}), 7.30(\mathrm{~d}, J=8.6 \mathrm{~Hz}$, 1H), 7.25-7.20 (m, 1H), $7.15(\mathrm{~d}, J=8.2 \mathrm{~Hz}, 2 \mathrm{H}), 6.67(\mathrm{~s}, 1 \mathrm{H}), 6.61(\mathrm{~s}, 2 \mathrm{H}), 1.21(\mathrm{~s}, 9 \mathrm{H}) .{ }^{13} \mathrm{C}$ NMR $\left(100 \mathrm{MHz}\right.$, DMSO-d $\left.{ }_{6}\right) \delta 176.73,162.69,159.66,158.48,138.81,134.75,133.48,130.41$, $129.76,128.17,125.00,124.79,121.01,120.57,113.75,113.35,112.72,31.39,27.46$. HRMS calcd for $\mathrm{C}_{23} \mathrm{H}_{23} \mathrm{BrN}_{5} \mathrm{O}^{+}[\mathrm{M}+\mathrm{H}]^{+} 464.1080$, found 464.1079 . HPLC purity $96.11 \%\left(\mathrm{t}_{\mathrm{R}}=11.1 \mathrm{~min}\right)$.

3.1.13. N-(4-(2-amino-4-(5-bromo- $1 H$-indol-3-yl) pyrimidin-5-yl) phenyl)-2-phenylacetamide A5

Yield: 35\%, pale yellow solid, mp 207.6-208.4 ${ }^{\circ} \mathrm{C} .{ }^{1} \mathrm{H}$ NMR (400 MHz, DMSO- $\left.d_{6}\right) \delta$ $11.42(\mathrm{~s}, 1 \mathrm{H}), 10.26(\mathrm{~s}, 1 \mathrm{H}), 8.57(\mathrm{~s}, 1 \mathrm{H}), 8.00(\mathrm{~s}, 1 \mathrm{H}), 7.64(\mathrm{~d}, J=8.3 \mathrm{~Hz}, 2 \mathrm{H}), 7.36(\mathrm{~d}, J=2.0 \mathrm{~Hz}$, $2 \mathrm{H}), 7.33(\mathrm{~d}, J=3.6 \mathrm{~Hz}, 2 \mathrm{H}), 7.31(\mathrm{~d}, J=4.5 \mathrm{~Hz}, 1 \mathrm{H}), 7.30-7.20(\mathrm{~m}, 2 \mathrm{H}), 7.20(\mathrm{~d}, J=8.2 \mathrm{~Hz}$, 
2H), $6.68(\mathrm{~s}, 1 \mathrm{H}), 6.62(\mathrm{~s}, 2 \mathrm{H}), 3.66(\mathrm{~s}, 2 \mathrm{H}) .{ }^{13} \mathrm{C}$ NMR $\left(100 \mathrm{MHz}, \mathrm{DMSO}-d_{6}\right) \delta 169.13,162.46$, $159.44,158.19,138.38,135.98,134.49,133.36,130.16,129.84,129.11,128.32,127.90,126.56$, $124.72,124.53,120.73,119.35,113.49,113.09,112.47,43.40$. HRMS calcd for $\mathrm{C}_{26} \mathrm{H}_{21} \mathrm{BrN}_{5} \mathrm{O}^{+}$ $[\mathrm{M}+\mathrm{H}]^{+}$498.0924, found 498.0924. HPLC purity $95.64 \%\left(\mathrm{t}_{\mathrm{R}}=11.8 \mathrm{~min}\right)$.

3.1.14. N-(4-(2-amino-4-(5-bromo-1H-indol-3-yl) pyrimidin-5-yl) phenyl) Benzamide A6 Yield: $43 \%$, pale yellow solid, mp $187.9-188.6{ }^{\circ} \mathrm{C} .{ }^{1} \mathrm{H}$ NMR $\left(400 \mathrm{MHz}, \mathrm{DMSO}-d_{6}\right) \delta$ $11.10(\mathrm{~s}, 1 \mathrm{H}), 10.13(\mathrm{~s}, 1 \mathrm{H}), 9.21(\mathrm{~d}, J=2.0 \mathrm{~Hz}, 1 \mathrm{H}), 8.52(\mathrm{~s}, 1 \mathrm{H}), 8.47(\mathrm{~d}, J=7.5 \mathrm{~Hz}, 2 \mathrm{H})$, $8.37(\mathrm{~d}, J=8.5 \mathrm{~Hz}, 2 \mathrm{H}), 8.03(\mathrm{~d}, J=7.3 \mathrm{~Hz}, 1 \mathrm{H}), 7.97(\mathrm{t}, J=7.5 \mathrm{~Hz}, 2 \mathrm{H}), 7.82(\mathrm{~d}, J=8.6 \mathrm{~Hz}$, $1 \mathrm{H}), 7.76(\mathrm{~d}, J=8.5 \mathrm{~Hz}, 2 \mathrm{H}), 7.71(\mathrm{dd}, J=8.6,2.0 \mathrm{~Hz}, 1 \mathrm{H}), 7.32(\mathrm{~s}, 1 \mathrm{H}), 6.55(\mathrm{~s}, 2 \mathrm{H}) .{ }^{13} \mathrm{C}$ NMR (100 MHz, DMSO-d $)_{6} \delta 175.94,173.23,170.46,168.93,149.17,145.75,145.40,144.73$, $141.90,140.83,140.34,138.92,138.81,137.84,135.79,135.21,132.19,130.81$. HRMS calcd for $\mathrm{C}_{25} \mathrm{H}_{19} \mathrm{BrN}_{5} \mathrm{O}^{+}[\mathrm{M}+\mathrm{H}]^{+} 484.0767$, found 484.0770 . HPLC purity $95.56 \%\left(\mathrm{t}_{\mathrm{R}}=12.6 \mathrm{~min}\right)$.

3.1.15. $N$-(4-(2-amino-4-(5-bromo-1H-indol-3-yl) pyrimidin-5-yl) phenyl)-2-fluorobenzamide A7

Yield: $37 \%$, pale yellow solid, mp $159.6-160.4{ }^{\circ} \mathrm{C} .{ }^{1} \mathrm{H}$ NMR $\left(400 \mathrm{MHz}\right.$, DMSO- $\left.d_{6}\right) \delta$ $10.51(\mathrm{~s}, 1 \mathrm{H}), 8.57(\mathrm{~s}, 1 \mathrm{H}), 8.01(\mathrm{~s}, 1 \mathrm{H}), 7.77(\mathrm{~d}, J=8.1 \mathrm{~Hz}, 2 \mathrm{H}), 7.69(\mathrm{~s}, 2 \mathrm{H}), 7.59(\mathrm{~d}, J=6.5 \mathrm{~Hz}$, $1 \mathrm{H}), 7.36(\mathrm{q}, J=8.3,7.2 \mathrm{~Hz}, 3 \mathrm{H}), 7.24(\mathrm{t}, J=8.1 \mathrm{~Hz}, 3 \mathrm{H}), 6.77(\mathrm{~s}, 1 \mathrm{H}), 6.61(\mathrm{~s}, 2 \mathrm{H}) .{ }^{13} \mathrm{C}$ NMR (100 MHz, DMSO-d $\left.d_{6}\right) \delta 175.41,163.29,162.95,160.57,159.97,158.71,158.10,138.52$, $135.13,134.52,132.97(\mathrm{~d}, J=9.2 \mathrm{~Hz}), 130.81,130.34,128.41,125.51(\mathrm{~d}, J=15.3 \mathrm{~Hz}), 125.10$ $(\mathrm{d}, J=8.8 \mathrm{~Hz}), 124.97(\mathrm{~d}, J=11.1 \mathrm{~Hz}), 121.11,120.43,116.63(\mathrm{~d}, J=21.7 \mathrm{~Hz}), 114.13,113.53$, 112.81. HRMS calcd for $\mathrm{C}_{25} \mathrm{H}_{18} \mathrm{BrFN}_{5} \mathrm{O}^{+}$, $[\mathrm{M}+\mathrm{H}]{ }^{+}$502.0673, found 502.0668. HPLC purity $95.43 \%\left(t_{R}=12.0 \mathrm{~min}\right)$.

3.1.16. N-(4-(2-amino-4-(5-bromo-1H-indol-3-yl) pyrimidiN-5-yl) phenyl)-3-fluorobenzamide A8

Yield: $41 \%$, pale yellow solid, mp 183.6-184. $3{ }^{\circ} \mathrm{C} .{ }^{1} \mathrm{H}$ NMR $\left(400 \mathrm{MHz}, \mathrm{DMSO}-d_{6}\right) \delta$ $11.48(\mathrm{~s}, 1 \mathrm{H}), 10.40(\mathrm{~s}, 1 \mathrm{H}), 8.57(\mathrm{~d}, J=2.0 \mathrm{~Hz}, 1 \mathrm{H}), 8.04(\mathrm{~s}, 1 \mathrm{H}), 7.85-7.76(\mathrm{~m}, 4 \mathrm{H}), 7.64-7.56$ $(\mathrm{m}, 1 \mathrm{H}), 7.49-7.43(\mathrm{~m}, 1 \mathrm{H}), 7.33(\mathrm{~d}, J=8.6 \mathrm{~Hz}, 1 \mathrm{H}), 7.29-7.24(\mathrm{~m}, 3 \mathrm{H}), 6.75(\mathrm{~d}, J=2.9 \mathrm{~Hz}$, $1 \mathrm{H}), 6.63(\mathrm{~s}, 2 \mathrm{H}) .{ }^{13} \mathrm{C}$ NMR $\left(100 \mathrm{MHz}\right.$, DMSO-d $\left.d_{6}\right) \delta 164.23,163.18,162.51,160.74,159.46$, $158.31,138.07,134.57,134.10,130.65(\mathrm{~d}, J=7.9 \mathrm{~Hz}), 130.16,129.79,127.93,124.73,124.59$, $123.92(\mathrm{~d}, J=2.6 \mathrm{~Hz}), 120.75,120.64(\mathrm{~d}, J=3.1 \mathrm{~Hz}), 114.63,114.40,113.55,113.14,112.54$. HRMS calcd for $\mathrm{C}_{25} \mathrm{H}_{18} \mathrm{BrFN}_{5} \mathrm{O}^{+}$, [M + H] ${ }^{+} 502.0673$, found 502.0673. HPLC purity $98.18 \%$ $\left(\mathrm{t}_{\mathrm{R}}=12.2 \mathrm{~min}\right)$.

3.1.17. N-(4-(2-amino-4-(5-bromo-1H-indol-3-yl) pyrimidin-5-yl) phenyl)-4-fluorobenzamide A9

Yield: $38 \%$, pale yellow solid, mp 178.6-179.4 ${ }^{\circ} \mathrm{C} .{ }^{1} \mathrm{H}$ NMR $\left(400 \mathrm{MHz}\right.$, DMSO- $\left.d_{6}\right) \delta$ $11.47(\mathrm{~s}, 1 \mathrm{H}), 10.35(\mathrm{~s}, 1 \mathrm{H}), 8.58(\mathrm{~d}, J=2.0 \mathrm{~Hz}, 1 \mathrm{H}), 8.07-8.03(\mathrm{~m}, 3 \mathrm{H}), 7.82(\mathrm{~d}, J=8.4 \mathrm{~Hz}, 2 \mathrm{H})$, $7.38(\mathrm{t}, J=8.8 \mathrm{~Hz}, 2 \mathrm{H}), 7.33(\mathrm{~d}, J=8.6 \mathrm{~Hz}, 1 \mathrm{H}), 7.26(\mathrm{~d}, J=8.5 \mathrm{~Hz}, 3 \mathrm{H}), 6.74(\mathrm{~d}, J=2.9 \mathrm{~Hz}$, $1 \mathrm{H}), 6.63$ (s, 2H). ${ }^{13} \mathrm{C}$ NMR (100 MHz, DMSO- $\left.d_{6}\right) \delta$ 165.76, 164.94, 163.29, 162.92, 159.87, $158.72,138.68,134.98,134.32,131.81(\mathrm{~d}, J=3.0 \mathrm{~Hz}), 130.85(\mathrm{~d}, J=9.2 \mathrm{~Hz}), 130.57,130.18$, $128.35,125.07(\mathrm{~d}, J=14.9 \mathrm{~Hz}), 121.20,120.98,115.80(\mathrm{~d}, J=22.0 \mathrm{~Hz}), 113.96,113.55,112.96$. HRMS calcd for $\mathrm{C}_{25} \mathrm{H}_{18} \mathrm{BrFN}_{5} \mathrm{O}^{+}[\mathrm{M}+\mathrm{H}]{ }^{+} 502.0673$, found 502.0669. HPLC purity $95.97 \%$ $\left(\mathrm{t}_{\mathrm{R}}=12.1 \mathrm{~min}\right)$.

3.1.18. N-(4-(2-amino-4-(5-bromo-1H-indol-3-yl) pyrimidin-5-yl) phenyl)-2-chlorobenzamide A10

Yield: $43 \%$, pale yellow solid, mp 211.5-212.4 ${ }^{\circ} \mathrm{C} .{ }^{1} \mathrm{H}$ NMR $\left(400 \mathrm{MHz}\right.$, DMSO- $\left.d_{6}\right) \delta$ $11.48(\mathrm{~s}, 1 \mathrm{H}), 10.59(\mathrm{~s}, 1 \mathrm{H}), 8.57(\mathrm{~s}, 1 \mathrm{H}), 8.03(\mathrm{~s}, 1 \mathrm{H}), 7.76(\mathrm{~d}, J=8.2 \mathrm{~Hz}, 2 \mathrm{H}), 7.62-7.57(\mathrm{~m}, 2 \mathrm{H})$, $7.53(\mathrm{~d}, J=7.9 \mathrm{~Hz}, 1 \mathrm{H}), 7.49(\mathrm{~d}, J=5.8 \mathrm{~Hz}, 1 \mathrm{H}), 7.46(\mathrm{~d}, J=7.3 \mathrm{~Hz}, 1 \mathrm{H}), 7.34(\mathrm{~d}, J=8.6 \mathrm{~Hz}$, $1 \mathrm{H}), 7.26(\mathrm{~d}, J=8.2 \mathrm{~Hz}, 2 \mathrm{H}), 6.77(\mathrm{~d}, J=2.9 \mathrm{~Hz}, 1 \mathrm{H}), 6.64(\mathrm{~s}, 2 \mathrm{H}) .{ }^{13} \mathrm{C}$ NMR $(100 \mathrm{MHz}$, DMSO- $\left.d_{6}\right) \delta 164.55,162.09,159.02,157.94,137.64,136.55,134.15,133.64,130.73,129.80$, $129.52,129.49,129.28,128.54,127.52,126.89,124.30,124.17,120.32,119.45,113.14,112.72$, 
112.09. HRMS calcd for $\mathrm{C}_{25} \mathrm{H}_{18} \mathrm{BrClN}_{5} \mathrm{O}^{+}[\mathrm{M}+\mathrm{H}]^{+}$518.0378, found 518.0381. HPLC purity $96.64 \%\left(t_{R}=12.1 \mathrm{~min}\right)$.

3.1.19. $N$-(4-(2-amino-4-(5-bromo-1H-indol-3-yl) pyrimidin-5-yl) phenyl)-3-chlorobenzamide A11

Yield: $36 \%$, pale yellow solid, mp 204.8-205.2 ${ }^{\circ} \mathrm{C} .{ }^{1} \mathrm{H}$ NMR $\left(400 \mathrm{MHz}\right.$, DMSO- $\left.d_{6}\right) \delta$ $11.46(\mathrm{~s}, 1 \mathrm{H}), 10.42(\mathrm{~s}, 1 \mathrm{H}), 8.55(\mathrm{~s}, 1 \mathrm{H}), 8.01(\mathrm{~d}, J=7.0 \mathrm{~Hz}, 2 \mathrm{H}), 7.92(\mathrm{~d}, J=7.7 \mathrm{~Hz}, 1 \mathrm{H}), 7.80$ $(\mathrm{d}, J=8.1 \mathrm{~Hz}, 2 \mathrm{H}), 7.66(\mathrm{~d}, J=7.3 \mathrm{~Hz}, 1 \mathrm{H}), 7.57(\mathrm{t}, J=7.8 \mathrm{~Hz}, 1 \mathrm{H}), 7.32(\mathrm{~d}, J=8.6 \mathrm{~Hz}, 1 \mathrm{H})$, $7.28-7.23(\mathrm{~m}, 3 \mathrm{H}), 6.73(\mathrm{~d}, J=2.8 \mathrm{~Hz}, 1 \mathrm{H}), 6.62(\mathrm{~s}, 2 \mathrm{H}) .{ }^{13} \mathrm{C} \mathrm{NMR}\left(100 \mathrm{MHz}, \mathrm{DMSO}-d_{6}\right) \delta$ $164.13,162.51,159.44,158.35,158.31,138.06,136.91,134.57,134.11,133.25,131.44,130.46$, $130.15,129.78,127.43,126.52,124.72,124.58,120.74,120.60,113.54,113.13,112.53$. HRMS calcd for $\mathrm{C}_{25} \mathrm{H}_{18} \mathrm{BrClN}_{5} \mathrm{O}^{+}$, $[\mathrm{M}+\mathrm{H}]{ }^{+} 518.0378$, found 518.0371 . HPLC purity $95.15 \%$ $\left(t_{R}=13.1 \mathrm{~min}\right)$.

3.1.20. N-(4-(2-amino-4-(5-bromo-1H-indol-3-yl) pyrimidin-5-yl) phenyl)-4-chlorobenzamide A12

Yield: $42 \%$, pale yellow solid, $\mathrm{mp} 261.7-262.5{ }^{\circ} \mathrm{C} .{ }^{1} \mathrm{H}$ NMR $\left(400 \mathrm{MHz}\right.$, DMSO- $\left.d_{6}\right) \delta$ $11.47(\mathrm{~s}, 1 \mathrm{H}), 10.40(\mathrm{~s}, 1 \mathrm{H}), 8.58(\mathrm{~d}, J=2.2 \mathrm{~Hz}, 1 \mathrm{H}), 8.04(\mathrm{~s}, 1 \mathrm{H}), 8.01(\mathrm{~d}, J=8.6 \mathrm{~Hz}, 2 \mathrm{H}), 7.82$ $(\mathrm{d}, J=8.3 \mathrm{~Hz}, 2 \mathrm{H}), 7.62(\mathrm{~d}, J=8.7 \mathrm{~Hz}, 2 \mathrm{H}), 7.33(\mathrm{~d}, J=8.6 \mathrm{~Hz}, 1 \mathrm{H}), 7.27(\mathrm{~d}, J=8.4 \mathrm{~Hz}, 3 \mathrm{H})$, $6.74(\mathrm{~s}, 1 \mathrm{H}), 6.64(\mathrm{~s}, 2 \mathrm{H}) .{ }^{13} \mathrm{C}$ NMR $\left(100 \mathrm{MHz}, \mathrm{DMSO}-d_{6}\right) \delta 164.70,162.71,159.65,158.49$, $138.36,136.65,134.76,134.21,133.85,130.35,129.97,129.86,128.70,128.13,124.93,124.77$, $120.96,120.78,113.73,113.33,112.74$. HRMS calcd for $\mathrm{C}_{25} \mathrm{H}_{18} \mathrm{BrClN}_{5} \mathrm{O}^{+}[\mathrm{M}+\mathrm{H}]{ }^{+}$518.0378, found 518.0385 . HPLC purity $96.20 \%\left(t_{R}=12.9 \mathrm{~min}\right)$.

3.1.21. N-(4-(2-amino-4-(5-bromo-1H-indol-3-yl) pyrimidin-5-yl) phenyl)-2-bromobenzamide A13

Yield: $46 \%$, pale yellow solid, mp $147.4-148.3{ }^{\circ} \mathrm{C} .{ }^{1} \mathrm{H}$ NMR $\left(400 \mathrm{MHz}\right.$, DMSO- $\left.d_{6}\right) \delta$ $11.49(\mathrm{~s}, 1 \mathrm{H}), 10.58(\mathrm{~s}, 1 \mathrm{H}), 8.59(\mathrm{~s}, 1 \mathrm{H}), 8.04(\mathrm{~s}, 1 \mathrm{H}), 7.80-7.71(\mathrm{~m}, 3 \mathrm{H}), 7.61-7.57(\mathrm{~m}, 1 \mathrm{H})$, $7.52(\mathrm{t}, J=7.5 \mathrm{~Hz}, 1 \mathrm{H}), 7.44(\mathrm{td}, J=7.7,1.9 \mathrm{~Hz}, 1 \mathrm{H}), 7.35(\mathrm{~d}, J=8.7 \mathrm{~Hz}, 1 \mathrm{H}), 7.29-7.25$ $(\mathrm{m}, 3 \mathrm{H}), 6.78(\mathrm{~d}, J=2.8 \mathrm{~Hz}, 1 \mathrm{H}), 6.65(\mathrm{~s}, 2 \mathrm{H}) .{ }^{13} \mathrm{C}$ NMR $\left(100 \mathrm{MHz}, \mathrm{DMSO}-d_{6}\right) \delta 165.38$, $162.07,158.96,157.92,138.68,137.64,134.11,133.60,132.31,130.78,129.75,129.45,128.44$, $127.50,127.32,124.28,124.13,120.28,119.42,118.57,113.09,112.68,112.06$. HRMS calcd for $\mathrm{C}_{25} \mathrm{H}_{18} \mathrm{Br}_{2} \mathrm{~N}_{5} \mathrm{O}^{+},[\mathrm{M}+\mathrm{H}]^{+} 561.9873$, found 561.9870 . HPLC purity $96.11 \%\left(\mathrm{t}_{\mathrm{R}}=12.1 \mathrm{~min}\right)$.

3.1.22. $N$-(4-(2-amino-4-(5-bromo-1H-indol-3-yl) pyrimidin-5-yl) phenyl)-3-bromobenzamide A14

Yield: $38 \%$, pale yellow solid, mp 176.6-177.3 ${ }^{\circ} \mathrm{C} .{ }^{1} \mathrm{H}$ NMR $\left(400 \mathrm{MHz}\right.$, DMSO- $\left.d_{6}\right) \delta$ $11.48(\mathrm{~s}, 1 \mathrm{H}), 10.44(\mathrm{~s}, 1 \mathrm{H}), 8.58(\mathrm{~d}, J=2.1 \mathrm{~Hz}, 1 \mathrm{H}), 8.20-8.13(\mathrm{~m}, 1 \mathrm{H}), 8.04(\mathrm{~s}, 1 \mathrm{H}), 7.98(\mathrm{~d}$, $J=7.8 \mathrm{~Hz}, 1 \mathrm{H}), 7.86-7.77(\mathrm{~m}, 3 \mathrm{H}), 7.52(\mathrm{t}, J=7.8 \mathrm{~Hz}, 1 \mathrm{H}), 7.34(\mathrm{~d}, J=8.6 \mathrm{~Hz}, 1 \mathrm{H}), 7.31-7.23$ $(\mathrm{m}, 3 \mathrm{H}), 6.75(\mathrm{~d}, J=2.9 \mathrm{~Hz}, 1 \mathrm{H}), 6.64(\mathrm{~s}, 2 \mathrm{H}) .{ }^{13} \mathrm{C}$ NMR $\left(100 \mathrm{MHz}, \mathrm{DMSO}-d_{6}\right) \delta 164.40$, 162.91, 159.82, 158.70, 138.45, 137.50, 134.95, 134.73, 134.51, 131.08, 130.66, 130.54, 130.17, 128.32, 127.29, 125.12, 124.96, 122.11, 121.12, 120.98, 113.92, 113.51, 112.93. HRMS calcd for $\mathrm{C}_{25} \mathrm{H}_{18} \mathrm{Br}_{2} \mathrm{~N}_{5} \mathrm{O}^{+},[\mathrm{M}+\mathrm{H}]+561.9873$, found 561.9870 . HPLC purity $97.54 \%\left(t_{\mathrm{R}}=13.3 \mathrm{~min}\right)$.

3.1.23. N-(4-(2-amino-4-(5-bromo-1H-indol-3-yl) pyrimidin-5-yl) phenyl)-4-bromobenzamide A15

Yield: $48 \%$, pale yellow solid, mp $276.4-277.3{ }^{\circ} \mathrm{C} .{ }^{1} \mathrm{H}$ NMR $\left(400 \mathrm{MHz}\right.$, DMSO- $\left.d_{6}\right) \delta$ $11.47(\mathrm{~s}, 1 \mathrm{H}), 10.40(\mathrm{~s}, 1 \mathrm{H}), 8.57(\mathrm{~d}, J=2.0 \mathrm{~Hz}, 1 \mathrm{H}), 8.03(\mathrm{~s}, 1 \mathrm{H}), 7.93(\mathrm{~d}, J=8.5 \mathrm{~Hz}, 2 \mathrm{H}), 7.82$ $(\mathrm{d}, J=8.3 \mathrm{~Hz}, 2 \mathrm{H}), 7.76(\mathrm{~d}, J=8.3 \mathrm{~Hz}, 2 \mathrm{H}), 7.33(\mathrm{~d}, J=8.5 \mathrm{~Hz}, 1 \mathrm{H}), 7.26(\mathrm{~d}, J=8.5 \mathrm{~Hz}, 3 \mathrm{H})$, $6.74(\mathrm{~d}, J=2.9 \mathrm{~Hz}, 1 \mathrm{H}), 6.63(\mathrm{~s}, 2 \mathrm{H}) .{ }^{13} \mathrm{C}$ NMR $\left(100 \mathrm{MHz}, \mathrm{DMSO}-d_{6}\right) \delta 165.02,162.91,159.84$, $158.69,138.55,134.96,134.41,132.53,131.85,130.55,130.24,130.17,128.33,125.78,125.13$, $124.97,121.15,120.97,113.93,113.52,112.94$. HRMS calcd for $\mathrm{C}_{25} \mathrm{H}_{18} \mathrm{Br}_{2} \mathrm{~N}_{5} \mathrm{O}^{+}[\mathrm{M}+\mathrm{H}]^{+}$ 561.9873 , found 561.9878 . HPLC purity $95.23 \%\left(t_{R}=13.1 \mathrm{~min}\right)$. 
3.1.24. N-(4-(2-amino-4-(5-bromo-1H-indol-3-yl) pyrimidin-5-yl) phenyl)-2-(trifluoromethyl) Benzamide A16

Yield: $20 \%$, pale yellow solid, mp $163.6-164.3{ }^{\circ} \mathrm{C} .{ }^{1} \mathrm{H}$ NMR $\left(400 \mathrm{MHz}, \mathrm{DMSO}-d_{6}\right)$ $\delta 11.60(\mathrm{~s}, 1 \mathrm{H}), 10.70(\mathrm{~s}, 1 \mathrm{H}), 8.58(\mathrm{~d}, J=2.0 \mathrm{~Hz}, 1 \mathrm{H}), 8.04(\mathrm{~s}, 1 \mathrm{H}), 7.86(\mathrm{~d}, J=7.8 \mathrm{~Hz}$, $1 \mathrm{H}), 7.81(\mathrm{t}, J=7.5 \mathrm{~Hz}, 1 \mathrm{H}), 7.77-7.69(\mathrm{~m}, 4 \mathrm{H}), 7.35(\mathrm{~d}, J=8.6 \mathrm{~Hz}, 1 \mathrm{H}), 7.29-7.25(\mathrm{~m}, 3 \mathrm{H})$, $6.79(\mathrm{~s}, 1 \mathrm{H}), 6.68(\mathrm{~s}, 2 \mathrm{H}) .{ }^{13} \mathrm{C}$ NMR $\left(100 \mathrm{MHz}, \mathrm{DMSO}-d_{6}\right) \delta 165.69,162.57,159.50,158.45$, $138.10,136.24,134.65,134.19,132.74,130.30,130.17,129.98,128.62,126.45$ (q, $J=4.9 \mathrm{~Hz})$, 125.24(q, $J=274.0 \mathrm{~Hz}), 126.05,125.74,124.78,124.64,120.75,119.99,113.65,113.21,112.53$. HRMS calcd for $\mathrm{C}_{26} \mathrm{H}_{18} \mathrm{BrF}_{3} \mathrm{~N}_{5} \mathrm{O}^{+}[\mathrm{M}+\mathrm{H}]+552.0641$, found 552.0628 . HPLC purity $96.07 \%$ $\left(\mathrm{t}_{\mathrm{R}}=12.1 \mathrm{~min}\right)$.

3.1.25. N-(4-(2-amino-4-(5-bromo-1H-indol-3-yl) pyrimidin-5-yl) phenyl)-3-(trifluoromethyl) Benzamide A17

Yield: $43 \%$, pale yellow solid, mp $172.6-173.3^{\circ} \mathrm{C} .{ }^{1} \mathrm{H}$ NMR $\left(400 \mathrm{MHz}, \mathrm{DMSO}-d_{6}\right) \delta$ $11.49(\mathrm{~s}, 1 \mathrm{H}), 10.57(\mathrm{~s}, 1 \mathrm{H}), 8.58(\mathrm{~s}, 1 \mathrm{H}), 8.37-8.23(\mathrm{~m}, 2 \mathrm{H}), 8.06(\mathrm{~s}, 1 \mathrm{H}), 7.97(\mathrm{~d}, J=7.9 \mathrm{~Hz}$, $1 \mathrm{H}), 7.84(\mathrm{~d}, J=8.5 \mathrm{~Hz}, 2 \mathrm{H}), 7.79(\mathrm{~d}, J=7.9 \mathrm{~Hz}, 1 \mathrm{H}), 7.34(\mathrm{~d}, J=8.6 \mathrm{~Hz}, 1 \mathrm{H}), 7.29(\mathrm{~d}$, $J=8.3 \mathrm{~Hz}, 2 \mathrm{H}), 7.26(\mathrm{~d}, J=9.0 \mathrm{~Hz}, 1 \mathrm{H}), 6.77(\mathrm{~s}, 1 \mathrm{H}), 6.65(\mathrm{~s}, 2 \mathrm{H}) .{ }^{13} \mathrm{C} \mathrm{NMR}(100 \mathrm{MHz}$, DMSO-d $d_{6} \delta 164.09,162.53,159.46,158.32,137.98,135.81,134.58,134.23,131.86,130.15$, $129.78(\mathrm{~d}, J=4.8 \mathrm{~Hz}), 129.39,129.07,128.75,128.18$ (d, $J=3.6 \mathrm{~Hz}), 127.93,126.49,125.35(\mathrm{q}$, $J=273.7 \mathrm{~Hz}), 124.65(\mathrm{~d}, J=14.9 \mathrm{~Hz}), 124.28(\mathrm{q}, J=3.6 \mathrm{~Hz}), 120.73,113.53,113.13,112.56$. HRMS calcd for $\mathrm{C}_{26} \mathrm{H}_{18} \mathrm{BrF}_{3} \mathrm{~N}_{5} \mathrm{O}^{+}[\mathrm{M}+\mathrm{H}]+552.0641$, found 552.0640. HPLC purity $97.48 \%$ $\left(\mathrm{t}_{\mathrm{R}}=13.2 \mathrm{~min}\right)$.

3.1.26. N-(4-(2-amino-4-(5-bromo-1H-indol-3-yl) pyrimidin-5-yl) phenyl)-4-(trifluoromethyl) Benzamide A18

Yield: $43 \%$, pale yellow solid, mp 312.7-313.4 ${ }^{\circ} \mathrm{C} .{ }^{1} \mathrm{H}$ NMR $\left(400 \mathrm{MHz}, \mathrm{DMSO}-d_{6}\right)$ $\delta 11.48(\mathrm{~s}, 1 \mathrm{H}), 10.56(\mathrm{~s}, 1 \mathrm{H}), 8.56(\mathrm{~s}, 1 \mathrm{H}), 8.17(\mathrm{~d}, J=8.1 \mathrm{~Hz}, 2 \mathrm{H}), 8.04(\mathrm{~s}, 1 \mathrm{H}), 7.93(\mathrm{~d}$, $J=8.2 \mathrm{~Hz}, 2 \mathrm{H}), 7.83(\mathrm{~d}, J=8.5 \mathrm{~Hz}, 2 \mathrm{H}), 7.34(\mathrm{~d}, J=8.6 \mathrm{~Hz}, 1 \mathrm{H}), 7.29(\mathrm{~s}, 1 \mathrm{H}), 7.27-7.24(\mathrm{~m}$, $2 \mathrm{H}), 6.75(\mathrm{~d}, J=2.9 \mathrm{~Hz}, 1 \mathrm{H}), 6.64(\mathrm{~s}, 2 \mathrm{H}) .{ }^{13} \mathrm{C}$ NMR $\left(100 \mathrm{MHz}, \mathrm{DMSO}-d_{6}\right) \delta 164.89,162.93$, $159.87,158.72,139.20,138.42,134.99,134.65,132.35,131.97,131.66,130.40(\mathrm{~d}, J=32.8 \mathrm{~Hz})$, $129.05,128.34,125.86(\mathrm{q}, J=3.5 \mathrm{~Hz}), 125.80(\mathrm{~d}, J=279.0 \mathrm{~Hz}), 123.01(\mathrm{q}, J=3.5 \mathrm{~Hz}), 121.15$, 121.04, 113.96, 113.55, 112.96. HRMS calcd for $\mathrm{C}_{26} \mathrm{H}_{18} \mathrm{BrF}_{3} \mathrm{~N}_{5} \mathrm{O}^{+},[\mathrm{M}+\mathrm{H}]{ }^{+} 552.0641$, found 552.0636. HPLC purity $97.91 \%\left(t_{R}=12.9 \mathrm{~min}\right)$.

3.1.27. N-(4-(2-amino-4-(5-bromo-1H-indol-3-yl) pyrimidin-5-yl) phenyl)-2-methylbenzamide A19

Yield: 33\%, pale yellow solid, mp 170.7-171.6 ${ }^{\circ} \mathrm{C} .{ }^{1} \mathrm{H}$ NMR $\left(400 \mathrm{MHz}, \mathrm{DMSO}-d_{6}\right) \delta$ $10.34(\mathrm{~s}, 1 \mathrm{H}), 8.48(\mathrm{~s}, 1 \mathrm{H}), 7.93(\mathrm{~s}, 1 \mathrm{H}), 7.70(\mathrm{~d}, J=8.2 \mathrm{~Hz}, 2 \mathrm{H}), 7.38(\mathrm{~d}, J=7.1 \mathrm{~Hz}, 1 \mathrm{H}), 7.31$ $(\mathrm{d}, J=7.8 \mathrm{~Hz}, 1 \mathrm{H}), 7.28(\mathrm{~d}, J=5.3 \mathrm{~Hz}, 1 \mathrm{H}), 7.24(\mathrm{~d}, J=7.2 \mathrm{~Hz}, 2 \mathrm{H}), 7.20(\mathrm{~d}, J=7.1 \mathrm{~Hz}, 1 \mathrm{H})$, 7.18-7.13 (m, 3H), $6.69(\mathrm{~s}, 1 \mathrm{H}), 6.56(\mathrm{~s}, 2 \mathrm{H}), 2.31(\mathrm{~s}, 3 \mathrm{H}) .{ }^{13} \mathrm{C}$ NMR $\left(100 \mathrm{MHz}, \mathrm{DMSO}-d_{6}\right) \delta$ 167.57, 162.12, 159.12, 157.98, 138.08, 136.86, 134.87, 134.31, 133.38, 130.20, 130.00, 129.44, 129.32, 127.59, 126.88, 125.34, 124.35, 124.16, 120.40, 119.54, 113.29, 112.75, 112.09, 19.00 . HRMS calcd for $\mathrm{C}_{26} \mathrm{H}_{21} \mathrm{BrN}_{5} \mathrm{O}^{+}[\mathrm{M}+\mathrm{H}]{ }^{+}$498.0924, found 498.0921. HPLC purity $96.94 \%$ $\left(\mathrm{t}_{\mathrm{R}}=12.2 \mathrm{~min}\right)$.

3.1.28. N-(4-(2-amino-4-(5-bromo-1H-indol-3-yl) pyrimidin-5-yl) phenyl)-3-methylbenzamide A20

Yield: $42 \%$, pale yellow solid, mp $211.8-212.9{ }^{\circ} \mathrm{C} .{ }^{1} \mathrm{H}$ NMR (400 MHz, DMSO- $d_{6}$ ) $\delta 11.45(\mathrm{~s}, 1 \mathrm{H}), 10.23(\mathrm{~s}, 1 \mathrm{H}), 8.49(\mathrm{~s}, 1 \mathrm{H}), 7.93(\mathrm{~s}, 1 \mathrm{H}), 7.74(\mathrm{~d}, J=8.2 \mathrm{~Hz}, 2 \mathrm{H}), 7.67(\mathrm{~d}$, $J=12.5 \mathrm{~Hz}, 2 \mathrm{H}), 7.32(\mathrm{~d}, J=5.8 \mathrm{~Hz}, 2 \mathrm{H}), 7.24(\mathrm{~d}, J=8.6 \mathrm{~Hz}, 1 \mathrm{H}), 7.15(\mathrm{~d}, J=8.3 \mathrm{~Hz}, 3 \mathrm{H})$, $6.64(\mathrm{~s}, 1 \mathrm{H}), 6.56(\mathrm{~s}, 2 \mathrm{H}), 2.30(\mathrm{~s}, 3 \mathrm{H}) .{ }^{13} \mathrm{C}$ NMR (100 MHz, DMSO-d 6 ) $\delta 166.44,163.17$, $160.15,158.97,139.10,138.43,135.65,135.24,134.44,132.88,130.88,130.41,129.02,128.85$, $128.61,125.54,125.42,125.26,121.45,121.16,114.25,113.82,113.18,21.68$. HRMS calcd for $\mathrm{C}_{26} \mathrm{H}_{21} \mathrm{BrN}_{5} \mathrm{O}^{+}[\mathrm{M}+\mathrm{H}]^{+} 498.0924$, found 498.0923. HPLC purity $95.11 \%\left(\mathrm{t}_{\mathrm{R}}=12.4 \mathrm{~min}\right)$. 
3.1.29. $N$-(4-(2-amino-4-(5-bromo-1H-indol-3-yl) pyrimidin-5-yl) phenyl)-4-methylbenzamide A21

Yield: $42 \%$, pale yellow solid, mp 291.7-292.4 ${ }^{\circ} \mathrm{C} .{ }^{1} \mathrm{H}$ NMR $\left(400 \mathrm{MHz}\right.$, DMSO- $\left.d_{6}\right) \delta$ $11.47(\mathrm{~s}, 1 \mathrm{H}), 10.24(\mathrm{~s}, 1 \mathrm{H}), 8.58(\mathrm{~s}, 1 \mathrm{H}), 8.04(\mathrm{~s}, 1 \mathrm{H}), 7.89(\mathrm{~d}, J=7.9 \mathrm{~Hz}, 2 \mathrm{H}), 7.83(\mathrm{~d}, J=8.6 \mathrm{~Hz}$, $2 \mathrm{H}), 7.37-7.31(\mathrm{~m}, 3 \mathrm{H}), 7.25(\mathrm{~d}, J=8.5 \mathrm{~Hz}, 3 \mathrm{H}), 6.74(\mathrm{~s}, 1 \mathrm{H}), 6.63(\mathrm{~s}, 2 \mathrm{H}), 2.39(\mathrm{~s}, 3 \mathrm{H}) .{ }^{13} \mathrm{C}$ NMR $\left(100 \mathrm{MHz}\right.$, DMSO- $\left.d_{6}\right) \delta 165.82,162.90,159.86,158.67,142.03,138.85,134.95,134.09$, $132.48,130.56,130.11,129.34,128.34,128.12,125.15,124.97,121.21,120.89,113.93,113.52$, 112.94, 21.43. HRMS calcd for $\mathrm{C}_{26} \mathrm{H}_{21} \mathrm{BrN}_{5} \mathrm{O}^{+},[\mathrm{M}+\mathrm{H}]^{+}$498.0924, found 498.0930. HPLC purity $96.26 \%\left(\mathrm{t}_{\mathrm{R}}=12.9 \mathrm{~min}\right)$.

3.1.30. N-(4-(2-amino-4-(5-bromo-1H-indol-3-yl) pyrimidin-5-yl) phenyl)-2-methoxybenzamide A22

Yield: $22 \%$, pale yellow solid, mp 154.9-155.6 ${ }^{\circ} \mathrm{C} .{ }^{1} \mathrm{H}$ NMR (400 MHz, DMSO- $\left.d_{6}\right)$ $\delta 11.47(\mathrm{~s}, 1 \mathrm{H}), 10.21(\mathrm{~s}, 1 \mathrm{H}), 8.60(\mathrm{~s}, 1 \mathrm{H}), 8.03(\mathrm{~s}, 1 \mathrm{H}), 7.79(\mathrm{~d}, J=8.3 \mathrm{~Hz}, 2 \mathrm{H}), 7.65(\mathrm{~d}$, $J=5.8 \mathrm{~Hz}, 1 \mathrm{H}), 7.51(\mathrm{t}, J=7.8 \mathrm{~Hz}, 1 \mathrm{H}), 7.34(\mathrm{~d}, J=8.6 \mathrm{~Hz}, 1 \mathrm{H}), 7.27-7.23(\mathrm{~m}, 3 \mathrm{H}), 7.19(\mathrm{~d}$, $J=8.4 \mathrm{~Hz}, 1 \mathrm{H}), 7.08(\mathrm{t}, J=7.5 \mathrm{~Hz}, 1 \mathrm{H}), 6.75(\mathrm{~d}, J=2.9 \mathrm{~Hz}, 1 \mathrm{H}), 6.63(\mathrm{~s}, 2 \mathrm{H}), 3.91(\mathrm{~s}, 3 \mathrm{H}) .{ }^{13} \mathrm{C}$ NMR (100 MHz, DMSO-d $\left.d_{6}\right) \delta 164.37,162.24,159.30,158.01,156.28,138.04,134.35,133.47$, $131.85,130.03,129.63,129.46,127.75,124.79,124.54,124.39,120.59,120.33,119.75,113.34$, 112.95, 112.31, 111.82, 55.72. HRMS calcd for $\mathrm{C}_{26} \mathrm{H}_{21} \mathrm{BrN}_{5} \mathrm{O}_{2}{ }^{+}[\mathrm{M}+\mathrm{H}]+{ }^{+} 514.0873$, found 514.0869. HPLC purity $97.46 \%\left(\mathrm{t}_{\mathrm{R}}=13.1 \mathrm{~min}\right)$.

3.1.31. $N$-(4-(2-amino-4-(5-bromo-1H-indol-3-yl) pyrimidin-5-yl) phenyl)-3-methoxybenzamide A23

Yield: $43 \%$, pale yellow solid, mp $172.6-173.3{ }^{\circ} \mathrm{C} .{ }^{1} \mathrm{H}$ NMR $\left(400 \mathrm{MHz}\right.$, DMSO- $\left.d_{6}\right) \delta$ $11.61(\mathrm{~s}, 1 \mathrm{H}), 10.36(\mathrm{~s}, 1 \mathrm{H}), 8.57(\mathrm{~s}, 1 \mathrm{H}), 8.03(\mathrm{~s}, 1 \mathrm{H}), 7.83(\mathrm{~d}, J=8.2 \mathrm{~Hz}, 2 \mathrm{H}), 7.56(\mathrm{~d}, J=7.7 \mathrm{~Hz}$, $1 \mathrm{H}), 7.50(\mathrm{~s}, 1 \mathrm{H}), 7.45(\mathrm{t}, J=7.9 \mathrm{~Hz}, 1 \mathrm{H}), 7.34(\mathrm{~d}, J=8.5 \mathrm{~Hz}, 1 \mathrm{H}), 7.25(\mathrm{~d}, J=8.3 \mathrm{~Hz}, 3 \mathrm{H})$, 7.19-7.13 (m, 1H), $6.75(\mathrm{~s}, 1 \mathrm{H}), 6.65(\mathrm{~s}, 2 \mathrm{H}), 3.84(\mathrm{~s}, 3 \mathrm{H}) .{ }^{13} \mathrm{C}$ NMR $\left(100 \mathrm{MHz}\right.$, DMSO- $\left.d_{6}\right) \delta$ $165.05,162.15,159.16,158.86,157.95,137.96,136.01,134.26,133.54,129.89,129.40,129.30$, $127.59,124.39,124.24,120.44,120.30,119.58,117.04,113.27,112.81,112.59,112.15,55.03$. HRMS calcd for $\mathrm{C}_{26} \mathrm{H}_{21} \mathrm{BrN}_{5} \mathrm{O}_{2}{ }^{+}[\mathrm{M}+\mathrm{H}]{ }^{+} 514.0873$, found 514.0871. HPLC purity $98.12 \%$ $\left(t_{R}=12.1 \mathrm{~min}\right)$.

3.1.32. N-(4-(2-amino-4-(5-bromo-1H-indol-3-yl) pyrimidin-5-yl) phenyl)-4-methoxybenzamide A24

Yield: $51 \%$, pale yellow solid, mp 184.6-185.3 ${ }^{\circ} \mathrm{C} .{ }^{1} \mathrm{H}$ NMR $\left(400 \mathrm{MHz}\right.$, DMSO- $\left.d_{6}\right) \delta$ $11.47(\mathrm{~s}, 1 \mathrm{H}), 10.18(\mathrm{~s}, 1 \mathrm{H}), 8.58(\mathrm{~d}, J=2.0 \mathrm{~Hz}, 1 \mathrm{H}), 8.04(\mathrm{~s}, 1 \mathrm{H}), 7.98(\mathrm{~d}, J=8.8 \mathrm{~Hz}, 2 \mathrm{H})$, $7.82(\mathrm{~d}, J=8.6 \mathrm{~Hz}, 2 \mathrm{H}), 7.33(\mathrm{~d}, J=8.6 \mathrm{~Hz}, 1 \mathrm{H}), 7.24(\mathrm{~d}, J=8.5 \mathrm{~Hz}, 3 \mathrm{H}), 7.07(\mathrm{~d}, J=8.8 \mathrm{~Hz}$, $2 \mathrm{H}), 6.74(\mathrm{~d}, J=2.9 \mathrm{~Hz}, 1 \mathrm{H}), 6.62(\mathrm{~s}, 2 \mathrm{H}), 3.84(\mathrm{~s}, 3 \mathrm{H}) .{ }^{13} \mathrm{C}$ NMR $\left(100 \mathrm{MHz}, \mathrm{DMSO}-d_{6}\right) \delta$ $164.77,162.26,161.73,159.27,158.03,138.35,134.34,133.34,129.96,129.47,129.42,127.73$, $126.76,124.54,124.36,120.63,120.27,113.43,113.32,112.92,112.33,55.25$. HRMS calcd for $\mathrm{C}_{26} \mathrm{H}_{21} \mathrm{BrN}_{5} \mathrm{O}_{2}{ }^{+},[\mathrm{M}+\mathrm{H}]^{+} 514.0873$, found 514.0871. HPLC purity $96.66 \%\left(\mathrm{t}_{\mathrm{R}}=12.1 \mathrm{~min}\right)$.

3.1.33. $N$-(4-(2-amino-4-(5-bromo-1H-indol-3-yl) pyrimidin-5-yl) phenyl)-2,

5-difluorobenzamide A25

Yield: $36 \%$, pale yellow solid, mp $163.5-164.3{ }^{\circ} \mathrm{C} .{ }^{1} \mathrm{H}$ NMR $\left(400 \mathrm{MHz}, \mathrm{DMSO}-d_{6}\right) \delta$ $11.48(\mathrm{~s}, 1 \mathrm{H}), 10.59(\mathrm{~s}, 1 \mathrm{H}), 8.58(\mathrm{~d}, J=2.0 \mathrm{~Hz}, 1 \mathrm{H}), 8.03(\mathrm{~s}, 1 \mathrm{H}), 7.76(\mathrm{~d}, J=8.2 \mathrm{~Hz}, 2 \mathrm{H})$, 7.58-7.53 (m, 1H), 7.47-7.40 (m, 2H), 7.34 (d, J = 8.6 Hz, 1H), 7.29-7.24 (m, 3H), $6.75(\mathrm{~d}$, $J=2.9 \mathrm{~Hz}, 1 \mathrm{H}), 6.64(\mathrm{~s}, 2 \mathrm{H}) .{ }^{13} \mathrm{C}$ NMR $\left(100 \mathrm{MHz}, \mathrm{DMSO}-d_{6}\right) \delta 162.94,161.91,159.86,159.44$, $158.72,157.03,156.71,154.27,138.21,134.97,134.71,130.48(\mathrm{~d}, J=24.3 \mathrm{~Hz}), 128.35,126.68$ $(\mathrm{dd}, J=18.6,7.4 \mathrm{~Hz}), 125.07(\mathrm{~d}, J=12.5 \mathrm{~Hz}), 121.10,120.46,119.41(\mathrm{dd}, J=24.2,9.0 \mathrm{~Hz})$, $118.47(\mathrm{dd}, J=25.0,8.5 \mathrm{~Hz}), 116.65(\mathrm{dd}, J=25.8,3.6 \mathrm{~Hz}), 113.97,113.56,112.91$. HRMS calcd for $\mathrm{C}_{25} \mathrm{H}_{17} \mathrm{BrF}_{2} \mathrm{~N}_{5} \mathrm{O}^{+},[\mathrm{M}+\mathrm{H}]{ }^{+} 520.0579$, found 520.0586 . HPLC purity $95.42 \%$ $\left(t_{R}=12.4 \mathrm{~min}\right)$. 
3.1.34. N-(4-(2-amino-4-(5-bromo-1H-indol-3-yl) pyrimidin-5-yl) phenyl)-3, 5-dichlorobenzamide A26

Yield: 33\%, pale yellow solid, mp 177.7-178.5 ${ }^{\circ} \mathrm{C} .{ }^{1} \mathrm{H}$ NMR (400 MHz, DMSO- $\left.d_{6}\right) \delta$ $11.49(\mathrm{~s}, 1 \mathrm{H}), 10.51(\mathrm{~s}, 1 \mathrm{H}), 8.57(\mathrm{~s}, 1 \mathrm{H}), 8.04(\mathrm{~s}, 1 \mathrm{H}), 8.00(\mathrm{~d}, J=2.0 \mathrm{~Hz}, 2 \mathrm{H}), 7.87(\mathrm{~s}, 1 \mathrm{H})$, $7.81(\mathrm{~d}, J=8.5 \mathrm{~Hz}, 2 \mathrm{H}), 7.34(\mathrm{~d}, J=8.6 \mathrm{~Hz}, 1 \mathrm{H}), 7.27(\mathrm{t}, J=10.2 \mathrm{~Hz}, 3 \mathrm{H}), 6.75(\mathrm{~d}, J=3.0 \mathrm{~Hz}$, $1 \mathrm{H}), 6.65$ (s, 2H). ${ }^{13} \mathrm{C}$ NMR (100 MHz, DMSO- $\left.d_{6}\right) \delta 162.28,162.09,158.99,157.86,137.66$, $137.35,134.13,133.90,130.53,129.68,129.38,127.48,126.59,126.09,124.27,124.13,120.25$, $120.20,113.09,112.68,112.09$. HRMS calcd for $\mathrm{C}_{25} \mathrm{H}_{17} \mathrm{BrCl}_{2} \mathrm{~N}_{5} \mathrm{O}^{+},[\mathrm{M}+\mathrm{H}]{ }^{+} 551.9988$, found 551.9988. HPLC purity $97.16 \%\left(t_{R}=13.2 \mathrm{~min}\right)$.

3.1.35. $N$-(4-(2-amino-4-(5-bromo-1H-indol-3-yl) pyrimidin-5-yl) phenyl) thiophene-2-carboxamide A27

Yield: $15 \%$, pale yellow solid, mp 303.8-304.4 ${ }^{\circ} \mathrm{C} .{ }^{1} \mathrm{H}$ NMR $\left(400 \mathrm{MHz}, \mathrm{DMSO}-d_{6}\right) \delta$ $11.63(\mathrm{~s}, 1 \mathrm{H}), 10.39(\mathrm{~s}, 1 \mathrm{H}), 8.57(\mathrm{~s}, 1 \mathrm{H}), 8.06(\mathrm{~d}, J=15.0 \mathrm{~Hz}, 2 \mathrm{H}), 7.87(\mathrm{~d}, J=5.0 \mathrm{~Hz}, 1 \mathrm{H})$, $7.79(\mathrm{~d}, J=8.1 \mathrm{~Hz}, 2 \mathrm{H}), 7.34(\mathrm{~d}, J=8.6 \mathrm{~Hz}, 1 \mathrm{H}), 7.26(\mathrm{~d}, J=8.4 \mathrm{~Hz}, 4 \mathrm{H}), 6.70(\mathrm{~d}, J=27.3 \mathrm{~Hz}$, 3H). ${ }^{13} \mathrm{C}$ NMR $\left(100 \mathrm{MHz}, \mathrm{DMSO}-d_{6}\right) \delta 162.93,160.37,159.90,158.72,140.49,138.38,135.03$, 134.33, 132.40, 130.66, 130.23, 129.67, 128.57, 128.36, 125.15, 124.97, 121.13, 120.96, 114.03, 113.54, 112.92. HRMS calcd for $\mathrm{C}_{23} \mathrm{H}_{17} \mathrm{BrN}_{5} \mathrm{OS}^{+}[\mathrm{M}+\mathrm{H}]{ }^{+} 490.0332$, found 490.0332. HPLC purity $95.22 \%\left(t_{R}=11.7 \mathrm{~min}\right)$.

3.1.36. $N$-(4-(2-amino-4-(5-bromo-1H-indol-3-yl) pyrimidin-5-yl) phenyl) isoquinoline-3-carboxamide A28

Yield: $43 \%$, pale yellow solid, mp $189.3-190.2{ }^{\circ} \mathrm{C} .{ }^{1} \mathrm{H}$ NMR $\left(400 \mathrm{MHz}, \mathrm{DMSO}-d_{6}\right) \delta$ $11.46(\mathrm{~s}, 1 \mathrm{H}), 10.81(\mathrm{~s}, 1 \mathrm{H}), 8.59(\mathrm{~d}, J=8.5 \mathrm{~Hz}, 1 \mathrm{H}), 8.52(\mathrm{~d}, J=2.0 \mathrm{~Hz}, 1 \mathrm{H}), 8.25-8.20(\mathrm{~m}$, 2H), 8.10-8.05 (m, 1H), 8.02 (s, 1H), 7.99-7.95 (m, 2H), 7.90-7.85 (m, 1H), 7.74-7.69 (m, 1H), $7.30-7.27(\mathrm{~m}, 2 \mathrm{H}), 7.25(\mathrm{~d}, J=2.0 \mathrm{~Hz}, 1 \mathrm{H}), 7.22-7.18(\mathrm{~m}, 1 \mathrm{H}), 6.71(\mathrm{~d}, J=2.8 \mathrm{~Hz}, 1 \mathrm{H}), 6.63(\mathrm{~s}$, 2H). ${ }^{13} \mathrm{C}$ NMR $(100 \mathrm{MHz}$, DMSO-d 6$) \delta 162.46,162.14,159.10,157.92,149.73,145.54,137.88$, $137.12,134.19,133.83,130.35,129.81,129.51,129.01,128.58,128.05,127.79,127.53,124.34$, $124.20,120.34,120.13,118.45,113.19,112.75,112.16$. HRMS calcd for $\mathrm{C}_{28} \mathrm{H}_{20} \mathrm{BrN}_{6} \mathrm{O}^{+}[\mathrm{M}+$ $\mathrm{H}]+535.0876$, found 535.0873. HPLC purity $95.84 \%\left(t_{R}=14.6 \mathrm{~min}\right)$.

3.1.37. N-(4-(2-amino-4-(5-bromo-1H-indol-3-yl) pyrimidin-5-yl) phenyl)-2-naphthamide A29

Yield: $43 \%$, pale yellow solid, mp $189.3-190.2{ }^{\circ} \mathrm{C} .{ }^{1} \mathrm{H}$ NMR $\left(400 \mathrm{MHz}, \mathrm{DMSO}-d_{6}\right)$ $\delta 11.51(\mathrm{~s}, 1 \mathrm{H}), 10.59$ (s, 1H), 8.60 (d, $J=7.1 \mathrm{~Hz}, 2 \mathrm{H}), 8.04(\mathrm{q}, J=11.1,7.4 \mathrm{~Hz}, 5 \mathrm{H}), 7.90$ $(\mathrm{d}, J=8.0 \mathrm{~Hz}, 2 \mathrm{H}), 7.75-7.58(\mathrm{~m}, 2 \mathrm{H}), 7.35(\mathrm{~d}, J=8.7 \mathrm{~Hz}, 1 \mathrm{H}), 7.28(\mathrm{~d}, J=9.0 \mathrm{~Hz}, 3 \mathrm{H})$, $6.72(\mathrm{~d}, J=43.7 \mathrm{~Hz}, 3 \mathrm{H}) .{ }^{13} \mathrm{C}$ NMR $\left(100 \mathrm{MHz}, \mathrm{DMSO}-d_{6}\right) \delta 166.10,162.82,159.89,158.64$, $138.78,134.95,134.65,134.19,132.57,132.44,130.58,130.14,129.36,128.44,128.39,128.27$, $128.05,127.27,125.07,124.96,124.84,121.17,120.95,113.97,113.52,112.86$. HRMS calcd for $\mathrm{C}_{29} \mathrm{H}_{21} \mathrm{BrN}_{5} \mathrm{O}^{+}[\mathrm{M}+\mathrm{H}]+534.0924$, found 534.0922. HPLC purity $98.46 \%\left(t_{R}=13.4 \mathrm{~min}\right)$.

3.1.38. 4-(5-Bromo-1H-indol-3-yl)- $N$-(2-fluorophenyl) pyrimidin-2-amine B1

Yield: $25 \%$, pale yellow solid, mp 206.6-207.1 ${ }^{\circ} \mathrm{C} .{ }^{1} \mathrm{H}$ NMR $\left(400 \mathrm{MHz}, \mathrm{DMSO}-d_{6}\right) \delta$ $11.88(\mathrm{~s}, 1 \mathrm{H}), 8.96(\mathrm{~s}, 1 \mathrm{H}), 8.43(\mathrm{~s}, 1 \mathrm{H}), 8.29(\mathrm{~s}, 1 \mathrm{H}), 8.20(\mathrm{~d}, J=5.3 \mathrm{~Hz}, 1 \mathrm{H}), 7.70-7.63(\mathrm{~m}$, $1 \mathrm{H}), 7.32(\mathrm{~d}, J=8.5 \mathrm{~Hz}, 1 \mathrm{H}), 7.25-7.08(\mathrm{~m}, 5 \mathrm{H}) .{ }^{13} \mathrm{C}$ NMR $\left(100 \mathrm{MHz}, \mathrm{DMSO}-d_{6}\right) \delta 162.71$, $161.10,157.53,157.22,154.78,136.21,130.77,128.25$ (d, $J=11.4 \mathrm{~Hz}), 127.32,126.46,125.47$ $(\mathrm{d}, J=7.3 \mathrm{~Hz}), 125.25,124.87,124.78(\mathrm{~d}, J=4.0 \mathrm{~Hz}), 116.29(\mathrm{~d}, J=19.8 \mathrm{~Hz}), 114.13(\mathrm{~d}$, $J=29.7 \mathrm{~Hz}), 113.58,107.68$. HRMS calcd for $\mathrm{C}_{18} \mathrm{H}_{13} \mathrm{BrFN}_{4}{ }^{+}[\mathrm{M}+\mathrm{H}]{ }^{+} 383.0302$, found 383.0301. HPLC purity $99.29 \%\left(t_{R}=14.1 \mathrm{~min}\right)$.

\subsubsection{4-(5-Bromo-1H-indol-3-yl)- $N$-(3-fluorophenyl) pyrimidin-2-amine B2}

Yield: $48 \%$, pale yellow solid, mp $211.8-212.4{ }^{\circ} \mathrm{C} .{ }^{1} \mathrm{H}$ NMR (400 MHz, DMSO- $\left.d_{6}\right)$ $\delta 11.93(\mathrm{~s}, 1 \mathrm{H}), 9.64(\mathrm{~s}, 1 \mathrm{H}), 8.67(\mathrm{~s}, 1 \mathrm{H}), 8.29(\mathrm{~s}, 2 \mathrm{H}), 7.72(\mathrm{~d}, J=12.4 \mathrm{~Hz}, 1 \mathrm{H}), 7.49(\mathrm{~d}$, $J=8.2 \mathrm{~Hz}, 1 \mathrm{H}), 7.35(\mathrm{~d}, J=8.6 \mathrm{~Hz}, 1 \mathrm{H}), 7.29-7.19(\mathrm{~m}, 3 \mathrm{H}), 6.66(\mathrm{t}, J=8.4 \mathrm{~Hz}, 1 \mathrm{H}) .{ }^{13} \mathrm{C}$ NMR $\left(100 \mathrm{MHz}, \mathrm{DMSO}-d_{6}\right) \delta 164.12,162.67,161.73,160.28,157.42,143.20$ (d, J = 11.4 Hz), 136.35, 
$130.99,130.44(\mathrm{~d}, J=9.7 \mathrm{~Hz}), 127.26,125.39,124.75,115.27,114.33(\mathrm{~d}, J=29.6 \mathrm{~Hz}), 113.62$, $108.46,107.85(\mathrm{~d}, J=21.1 \mathrm{~Hz}), 106.01(\mathrm{~d}, J=26.4 \mathrm{~Hz})$. HRMS calcd for $\mathrm{C}_{18} \mathrm{H}_{13} \mathrm{BrFN}_{4}{ }^{+}[\mathrm{M}+$ $\mathrm{H}]+383.0302$, found 383.0295 . HPLC purity $98.07 \%\left(t_{R}=14.2 \mathrm{~min}\right)$.

3.1.40. 4-(5-Bromo-1H-indol-3-yl)- $N$-(4-fluorophenyl) pyrimidin-2-amine B3

Yield: $41 \%$, pale yellow solid, $\operatorname{mp} 246.8-247.7^{\circ} \mathrm{C} .{ }^{1} \mathrm{H}$ NMR $\left(400 \mathrm{MHz}, \mathrm{DMSO}-d_{6}\right) \delta$ $12.02(\mathrm{~s}, 1 \mathrm{H}), 9.44(\mathrm{~s}, 1 \mathrm{H}), 8.65(\mathrm{~s}, 1 \mathrm{H}), 8.34(\mathrm{~s}, 1 \mathrm{H}), 8.27(\mathrm{~d}, J=5.3 \mathrm{~Hz}, 1 \mathrm{H}), 7.75-7.70(\mathrm{~m}, 2 \mathrm{H})$, $7.39(\mathrm{~d}, J=8.6 \mathrm{~Hz}, 1 \mathrm{H}), 7.26(\mathrm{~d}, J=9.0 \mathrm{~Hz}, 1 \mathrm{H}), 7.23(\mathrm{~d}, J=5.3 \mathrm{~Hz}, 1 \mathrm{H}), 7.13(\mathrm{t}, J=8.7 \mathrm{~Hz}$, 2H). ${ }^{13} \mathrm{C}$ NMR $\left(100 \mathrm{MHz}, \mathrm{DMSO}-d_{6}\right) \delta 162.53,161.51,159.55,157.77,156.42,155.41,136.45$, 135.25, 129.84, 126.20, 123.96 (d, $J=46.4 \mathrm{~Hz}), 120.75$ (d, $J=7.5 \mathrm{~Hz}), 114.47$ (d, $J=22.2 \mathrm{~Hz})$, 113.39, $112.76(\mathrm{~d}, J=37.2 \mathrm{~Hz}), 106.71$. HRMS calcd for $\mathrm{C}_{18} \mathrm{H}_{13} \mathrm{BrFN}_{4}{ }^{+}[\mathrm{M}+\mathrm{H}]{ }^{+} 383.0302$, found 383.0296 HPLC purity $96.24 \%\left(t_{R}=14.1 \mathrm{~min}\right)$.

\subsubsection{4-(5-Bromo-1H-indol-3-yl)- $N$-(2-chlorophenyl) pyrimidin-2-amine B4}

Yield: $41 \%$, pale yellow solid, mp $173.8-174.6{ }^{\circ} \mathrm{C} .{ }^{1} \mathrm{H}$ NMR $\left(400 \mathrm{MHz}, \mathrm{DMSO}-d_{6}\right) \delta$ $11.94(\mathrm{~s}, 1 \mathrm{H}), 8.74(\mathrm{~s}, 1 \mathrm{H}), 8.41(\mathrm{~s}, 1 \mathrm{H}), 8.36(\mathrm{~d}, J=2.7 \mathrm{~Hz}, 1 \mathrm{H}), 8.29(\mathrm{~d}, J=5.4 \mathrm{~Hz}, 1 \mathrm{H}), 7.83$ $(\mathrm{d}, J=8.3 \mathrm{~Hz}, 1 \mathrm{H}), 7.55(\mathrm{~d}, J=8.0 \mathrm{~Hz}, 1 \mathrm{H}), 7.43(\mathrm{~d}, J=7.8 \mathrm{~Hz}, 1 \mathrm{H}), 7.39(\mathrm{~d}, J=8.3 \mathrm{~Hz}, 1 \mathrm{H})$, $7.26(\mathrm{t}, J=6.8 \mathrm{~Hz}, 2 \mathrm{H}), 7.21(\mathrm{~d}, J=7.6 \mathrm{~Hz}, 1 \mathrm{H}) .{ }^{13} \mathrm{C}$ NMR $\left(100 \mathrm{MHz}, \mathrm{DMSO}-d_{6}\right) \delta 162.65$, 161.04, 157.64, 137.31, 136.19, 130.82, 130.15, 128.30, 128.06, 127.30, 126.98, 125.99, 125.24, $124.85,114.29,113.96,113.52,107.76$. HRMS calcd for $\mathrm{C}_{18} \mathrm{H}_{13} \mathrm{BrFN}_{4}{ }^{+}[\mathrm{M}+\mathrm{H}]{ }^{+} 399.0007$, found 399. 0002.HPLC purity $98.97 \%\left(t_{R}=15.7 \mathrm{~min}\right)$.

\subsubsection{4-(5-Bromo-1H-indol-3-yl)-N-(3-chlorophenyl) pyrimidin-2-amine B5}

Yield: $38 \%$, pale yellow solid, mp $210.3-211.4{ }^{\circ} \mathrm{C} .{ }^{1} \mathrm{H}$ NMR $\left(400 \mathrm{MHz}, \mathrm{DMSO}-d_{6}\right) \delta$ $12.23(\mathrm{~s}, 1 \mathrm{H}), 9.69(\mathrm{~s}, 1 \mathrm{H}), 8.73(\mathrm{~s}, 1 \mathrm{H}), 8.40(\mathrm{~s}, 1 \mathrm{H}), 8.38(\mathrm{~d}, J=5.4 \mathrm{~Hz}, 1 \mathrm{H}), 8.10(\mathrm{~s}, 1 \mathrm{H}), 7.83$ $(\mathrm{d}, J=8.1 \mathrm{~Hz}, 1 \mathrm{H}), 7.45(\mathrm{~d}, J=8.6 \mathrm{~Hz}, 1 \mathrm{H}), 7.35-7.30(\mathrm{~m}, 2 \mathrm{H}), 7.28(\mathrm{~d}, J=8.1 \mathrm{~Hz}, 1 \mathrm{H}), 7.13$ $(\mathrm{d}, J=7.9 \mathrm{~Hz}, 1 \mathrm{H}) .{ }^{13} \mathrm{C}$ NMR $\left(100 \mathrm{MHz}, \mathrm{DMSO}-d_{6}\right) \delta 161.83,159.32,156.51,142.18,135.47$, $130.14,130.03,126.40,124.53,123.87,123.14,121.21,120.66,117.35,113.59,113.33,112.70$, 107.64. HRMS calcd for $\mathrm{C}_{18} \mathrm{H}_{13} \mathrm{BrClN}_{4}{ }^{+}[\mathrm{M}+\mathrm{H}]{ }^{+} 399.0007$, found 399.0000. HPLC purity $96.15 \%\left(\mathrm{t}_{\mathrm{R}}=14.4 \mathrm{~min}\right)$.

\subsubsection{4-(5-Bromo-1H-indol-3-yl)- $N$-(4-chlorophenyl) pyrimidin-2-amine B6}

Yield: $43 \%$, pale yellow solid, mp $273.5-274.8{ }^{\circ} \mathrm{C} .{ }^{1} \mathrm{H}$ NMR $\left(400 \mathrm{MHz}, \mathrm{DMSO}-d_{6}\right) \delta$ $12.28(\mathrm{~s}, 1 \mathrm{H}), 9.58(\mathrm{~s}, 1 \mathrm{H}), 8.66(\mathrm{~s}, 1 \mathrm{H}), 8.36(\mathrm{~s}, 1 \mathrm{H}), 8.28(\mathrm{~d}, J=5.3 \mathrm{~Hz}, 1 \mathrm{H}), 7.77(\mathrm{~d}, J=8.8 \mathrm{~Hz}$, 2H), $7.40(\mathrm{~d}, J=8.6 \mathrm{~Hz}, 1 \mathrm{H}), 7.31(\mathrm{~d}, J=8.8 \mathrm{~Hz}, 2 \mathrm{H}), 7.28-7.23(\mathrm{~m}, 2 \mathrm{H}) .{ }^{13} \mathrm{C} \mathrm{NMR}(100 \mathrm{MHz}$, DMSO-d $\left.d_{6}\right) \delta 162.15,159.93,157.03,139.74,135.88,130.59,128.42,126.81,124.87,124.80$, $124.33,120.94,114.03,113.62,113.15,107.69$. HRMS calcd for $\mathrm{C}_{18} \mathrm{H}_{13} \mathrm{BrClN}_{4}{ }^{+},[\mathrm{M}+\mathrm{H}]$ +399.0007 , found 399.0005. HPLC purity $95.20 \%\left(t_{R}=15.4 \mathrm{~min}\right)$.

\subsubsection{4-(5-Bromo-1H-indol-3-yl)- $N$-(2-bromophenyl) pyrimidin-2-amine B7}

Yield: $37 \%$, pale yellow solid, mp $177.8-178.4{ }^{\circ} \mathrm{C} .{ }^{1} \mathrm{H}$ NMR $\left(400 \mathrm{MHz}, \mathrm{DMSO}-d_{6}\right) \delta$ $11.96(\mathrm{~s}, 1 \mathrm{H}), 8.71(\mathrm{~s}, 1 \mathrm{H}), 8.39-8.36(\mathrm{~m}, 2 \mathrm{H}), 8.28(\mathrm{~d}, J=5.3 \mathrm{~Hz}, 1 \mathrm{H}), 7.80(\mathrm{~d}, J=8.0 \mathrm{~Hz}$, $1 \mathrm{H}), 7.72(\mathrm{~d}, J=8.0 \mathrm{~Hz}, 1 \mathrm{H}), 7.46(\mathrm{t}, J=7.6 \mathrm{~Hz}, 1 \mathrm{H}), 7.39(\mathrm{~d}, J=8.6 \mathrm{~Hz}, 1 \mathrm{H}), 7.29-7.23(\mathrm{~m}$, 2H), $7.15(\mathrm{t}, J=7.7 \mathrm{~Hz}, 1 \mathrm{H}) .{ }^{13} \mathrm{C}$ NMR $\left(100 \mathrm{MHz}, \mathrm{DMSO}-d_{6}\right) \delta 162.63,161.06,157.65,138.64$, $136.18,133.31,130.88,130.80,128.71,127.30,126.53,125.22,124.86,119.55,114.27,113.94$, 113.52, 107.70. HRMS calcd for $\mathrm{C}_{18} \mathrm{H}_{13} \mathrm{Br}_{2} \mathrm{~N}_{4}{ }^{+}[\mathrm{M}+\mathrm{H}]{ }^{+} 442.9501$, found 442.9504. HPLC purity $98.68 \%\left(t_{R}=15.9 \mathrm{~min}\right)$.

\subsubsection{4-(5-Bromo-1H-indol-3-yl)- $N$-(3-bromophenyl) pyrimidin-2-amine B8}

Yield: $48 \%$, pale yellow solid, mp $214.8-215.6{ }^{\circ} \mathrm{C} .{ }^{1} \mathrm{H}$ NMR $\left(400 \mathrm{MHz}, \mathrm{DMSO}-d_{6}\right) \delta$ $12.04(\mathrm{~s}, 1 \mathrm{H}), 9.71(\mathrm{~s}, 1 \mathrm{H}), 8.73(\mathrm{~d}, J=2.0 \mathrm{~Hz}, 1 \mathrm{H}), 8.40(\mathrm{~d}, J=3.9 \mathrm{~Hz}, 1 \mathrm{H}), 8.38(\mathrm{~s}, 1 \mathrm{H}), 7.99$ $(\mathrm{s}, 1 \mathrm{H}), 7.79-7.71(\mathrm{~m}, 1 \mathrm{H}), 7.45(\mathrm{~d}, J=8.6 \mathrm{~Hz}, 1 \mathrm{H}), 7.36(\mathrm{~d}, J=8.4 \mathrm{~Hz}, 1 \mathrm{H}), 7.34-7.30(\mathrm{~m}, 2 \mathrm{H})$, 7.02-6.96 (m, 1H). ${ }^{13} \mathrm{C}$ NMR $\left(100 \mathrm{MHz}, \mathrm{DMSO}-d_{6}\right) \delta 161.82,159.34,156.53,142.01,135.46$, $132.64,130.15,129.71,126.38,124.52,123.85,120.24,117.80,116.97,113.59,113.30,112.70$, 
107.64. HRMS calcd for $\mathrm{C}_{18} \mathrm{H}_{13} \mathrm{Br}_{2} \mathrm{~N}_{4}{ }^{+}[\mathrm{M}+\mathrm{H}]^{+} 442.9501$, found 442.9498. HPLC purity $98.57 \%\left(t_{R}=15.1 \mathrm{~min}\right)$.

3.1.46. 4-(5-Bromo-1H-indol-3-yl)- $N$-(4-bromophenyl) pyrimidin-2-amine B9

Yield: $36 \%$, pale yellow solid, $\mathrm{mp} 276.7-277.5{ }^{\circ} \mathrm{C} .{ }^{1} \mathrm{H}$ NMR $\left(400 \mathrm{MHz}\right.$, DMSO- $\left.d_{6}\right) \delta$ $12.22(\mathrm{~s}, 1 \mathrm{H}), 9.55(\mathrm{~s}, 1 \mathrm{H}), 8.63(\mathrm{~s}, 1 \mathrm{H}), 8.32(\mathrm{~s}, 1 \mathrm{H}), 8.25(\mathrm{~d}, J=5.4 \mathrm{~Hz}, 1 \mathrm{H}), 7.69(\mathrm{~d}, J=8.5 \mathrm{~Hz}$, $2 \mathrm{H}), 7.44-7.33(\mathrm{~m}, 3 \mathrm{H}), 7.24-7.20(\mathrm{~m}, 2 \mathrm{H}) .{ }^{13} \mathrm{C}$ NMR $\left(100 \mathrm{MHz}, \mathrm{DMSO}-d_{6}\right) \delta 161.57,159.28$, $156.39,139.56,135.31,130.68,129.99,126.18,124.18,123.70,120.78,113.48,112.98,112.42$, 112.07, 107.12. HRMS calcd for $\mathrm{C}_{18} \mathrm{H}_{13} \mathrm{Br}_{2} \mathrm{~N}_{4}{ }^{+},[\mathrm{M}+\mathrm{H}]^{+}$442.9501, found 442.9502. HPLC purity $95.11 \%\left(t_{R}=15.7 \mathrm{~min}\right)$.

3.1.47. 4-(5-Bromo-1H-indol-3-yl)-N-(2-(trifluoromethyl) phenyl) pyrimidin-2-amine B10

Yield: $40 \%$, pale yellow solid, $\mathrm{mp} 150.5-151.3{ }^{\circ} \mathrm{C} .{ }^{1} \mathrm{H}$ NMR $\left(400 \mathrm{MHz}\right.$, DMSO- $\left.d_{6}\right) \delta$ $12.10(\mathrm{~s}, 1 \mathrm{H}), 8.68(\mathrm{~s}, 1 \mathrm{H}), 8.34(\mathrm{~s}, 1 \mathrm{H}), 8.26(\mathrm{~d}, J=5.3 \mathrm{~Hz}, 1 \mathrm{H}), 8.21(\mathrm{~s}, 1 \mathrm{H}), 7.78(\mathrm{~d}, J=8.2 \mathrm{~Hz}$, $3 \mathrm{H}), 7.47(\mathrm{~d}, J=7.6 \mathrm{~Hz}, 1 \mathrm{H}), 7.39(\mathrm{~d}, J=8.6 \mathrm{~Hz}, 1 \mathrm{H}), 7.28-7.21(\mathrm{~m}, 2 \mathrm{H}) .{ }^{13} \mathrm{C}$ NMR $(100 \mathrm{MHz}$, DMSO- $\left.d_{6}\right) \delta 162.51,161.89,157.49,138.26,136.06,133.55,130.58,130.00,127.18,126.75(\mathrm{q}$, $J=5.3 \mathrm{~Hz}), 126.07,125.74(\mathrm{q}, J=272 \mathrm{~Hz}), 125.04,124.70(\mathrm{~d}, J=5.7 \mathrm{~Hz}), 124.44,114.15,113.76$, 113.29, 107.41. HRMS calcd for $\mathrm{C}_{19} \mathrm{H}_{13} \mathrm{BrF}_{3} \mathrm{~N}_{4}{ }^{+},[\mathrm{M}+\mathrm{H}]{ }^{+} 433.0270$, found 433.0271. HPLC purity $95.40 \%\left(\mathrm{t}_{\mathrm{R}}=14.7 \mathrm{~min}\right)$.

3.1.48. 4-(5-Bromo- $1 H$-indol-3-yl)- $N$-(3-(trifluoromethyl) phenyl) pyrimidin-2-amine B11

Yield: $45 \%$, pale yellow solid, $\mathrm{mp} 171.8-172.3{ }^{\circ} \mathrm{C} .{ }^{1} \mathrm{H}$ NMR $\left(400 \mathrm{MHz}, \mathrm{DMSO}-d_{6}\right) \delta$ $12.02(\mathrm{~s}, 1 \mathrm{H}), 9.82(\mathrm{~s}, 1 \mathrm{H}), 8.72(\mathrm{~s}, 1 \mathrm{H}), 8.41(\mathrm{~d}, J=5.2 \mathrm{~Hz}, 2 \mathrm{H}), 8.22(\mathrm{~s}, 1 \mathrm{H}), 8.15(\mathrm{~d}, J=8.4 \mathrm{~Hz}$, $1 \mathrm{H}), 7.56(\mathrm{t}, J=8.0 \mathrm{~Hz}, 1 \mathrm{H}), 7.45(\mathrm{~d}, J=8.9 \mathrm{~Hz}, 1 \mathrm{H}), 7.35(\mathrm{t}, J=4.9 \mathrm{~Hz}, 2 \mathrm{H}), 7.32-7.27(\mathrm{~m}$, 1H). ${ }^{13} \mathrm{C}$ NMR $\left(100 \mathrm{MHz}\right.$, DMSO-d $\left.d_{6}\right) \delta 162.31,159.80,156.97,141.74,135.93,130.58,129.93$ $(\mathrm{q}, J=29.3 \mathrm{~Hz}), 129.00,126.83,125.79(\mathrm{q}, J=272.7 \mathrm{~Hz}) 124.97,124.27,122.45,117.22,114.90$, 114.04, 113.76, 113.12, 108.24. HRMS calcd for $\mathrm{C}_{19} \mathrm{H}_{13} \mathrm{BrF}_{3} \mathrm{~N}_{4}{ }^{+}$, $[\mathrm{M}+\mathrm{H}]^{+} 433.0270$, found 433.0278. HPLC purity $99.39 \%\left(t_{R}=15.1 \mathrm{~min}\right)$.

3.1.49. 4-(5-Bromo-1H-indol-3-yl)- $N$-(4-(trifluoromethyl) phenyl) pyrimidin-2-amine B12

Yield: $34 \%$, pale yellow solid, mp $279.5-280.3{ }^{\circ} \mathrm{C} .{ }^{1} \mathrm{H}$ NMR $\left(400 \mathrm{MHz}, \mathrm{DMSO}-d_{6}\right) \delta$ $12.02(\mathrm{~s}, 1 \mathrm{H}), 9.91(\mathrm{~s}, 1 \mathrm{H}), 8.76(\mathrm{~s}, 1 \mathrm{H}), 8.43(\mathrm{~d}, J=3.0 \mathrm{~Hz}, 1 \mathrm{H}), 8.41(\mathrm{~d}, J=5.4 \mathrm{~Hz}, 1 \mathrm{H}), 8.02$ $(\mathrm{d}, J=8.5 \mathrm{~Hz}, 2 \mathrm{H}), 7.68(\mathrm{~d}, J=8.5 \mathrm{~Hz}, 2 \mathrm{H}), 7.45(\mathrm{~d}, J=8.6 \mathrm{~Hz}, 1 \mathrm{H}), 7.38(\mathrm{~d}, J=5.4 \mathrm{~Hz}$, $1 \mathrm{H}), 7.35-7.31(\mathrm{~m}, 1 \mathrm{H}) .{ }^{13} \mathrm{C}$ NMR $\left(100 \mathrm{MHz}\right.$, DMSO- $\left.d_{6}\right) \delta 162.25,159.72,157.06,144.51$, 135.94, 130.76, 126.81, $125.87(\mathrm{~d}, J=4.1 \mathrm{~Hz}), 124.92,124.32,123.47(\mathrm{q}, J=272.7 \mathrm{~Hz}), 120.95$ $(\mathrm{q}, J=31.1 \mathrm{~Hz}), 118.75,114.08,113.66,113.09,108.36$. HRMS calcd for $\mathrm{C}_{19} \mathrm{H}_{13} \mathrm{BrF}_{3} \mathrm{~N}_{4}{ }^{+} \mathrm{M}+$ $\mathrm{H}]^{+} 433.0270$, found 433.0273 . HPLC purity $97.41 \%\left(\mathrm{t}_{\mathrm{R}}=15.3 \mathrm{~min}\right)$.

\subsubsection{4-(5-Bromo- $1 H$-indol-3-yl)- $N$-(o-tolyl) pyrimidin-2-amine B13}

Yield: $39 \%$, pale yellow solid, $\mathrm{mp} 187.6-188.4{ }^{\circ} \mathrm{C} .{ }^{1} \mathrm{H}$ NMR $\left(400 \mathrm{MHz}\right.$, DMSO- $\left.d_{6}\right) \delta$ $11.86(\mathrm{~s}, 1 \mathrm{H}), 8.65(\mathrm{~s}, 1 \mathrm{H}), 8.39-8.06(\mathrm{~m}, 3 \mathrm{H}), 7.38(\mathrm{~d}, J=57.8 \mathrm{~Hz}, 2 \mathrm{H}), 7.12(\mathrm{~d}, J=59.2 \mathrm{~Hz}$, $5 \mathrm{H}), 2.20(\mathrm{~s}, 3 \mathrm{H}) .{ }^{13} \mathrm{C}$ NMR $\left(100 \mathrm{MHz}\right.$, DMSO-d $\left.d_{6}\right) \delta 162.58,161.66,157.61,138.73,136.16$, $134.54,132.91,131.01,130.56,127.34,126.65,125.85,125.21,124.93,114.22,113.94,113.72$, 106.80, 18.80. HRMS calcd for $\mathrm{C}_{19} \mathrm{H}_{16} \mathrm{BrN}_{4}{ }^{+}[\mathrm{M}+\mathrm{H}]{ }^{+} 379.0553$, found 379.0561. HPLC purity $95.08 \%\left(t_{R}=14.4 \mathrm{~min}\right)$.

\subsubsection{4-(5-Bromo-1H-indol-3-yl)- $N$-(m-tolyl) pyrimidin-2-amine B14}

Yield: $52 \%$, pale yellow solid, $\mathrm{mp} 141.5-142.3{ }^{\circ} \mathrm{C} .{ }^{1} \mathrm{H}$ NMR $\left(400 \mathrm{MHz}\right.$, DMSO- $\left.d_{6}\right) \delta$ $12.00(\mathrm{~s}, 1 \mathrm{H}), 9.42(\mathrm{~s}, 1 \mathrm{H}), 8.76(\mathrm{~s}, 1 \mathrm{H}), 8.39(\mathrm{~s}, 1 \mathrm{H}), 8.34(\mathrm{~d}, J=5.3 \mathrm{~Hz}, 1 \mathrm{H}), 7.63(\mathrm{~d}, J=7.1 \mathrm{~Hz}$, $2 \mathrm{H}), 7.44(\mathrm{~d}, J=8.6 \mathrm{~Hz}, 1 \mathrm{H}), 7.34-7.30(\mathrm{~m}, 1 \mathrm{H}), 7.27(\mathrm{~d}, J=5.4 \mathrm{~Hz}, 1 \mathrm{H}), 7.25-7.19(\mathrm{~m}, 1 \mathrm{H})$, $6.80(\mathrm{~d}, J=7.5 \mathrm{~Hz}, 1 \mathrm{H}), 2.31(\mathrm{~s}, 3 \mathrm{H}) .{ }^{13} \mathrm{C}$ NMR $\left(100 \mathrm{MHz}, \mathrm{DMSO}-d_{6}\right) \delta 162.47,160.58,157.42$, $141.10,138.02,136.28,130.76,128.84,127.27,125.28,124.77,122.49,120.16,116.97,114.38$, 114.00, 113.76, 107.69, 21.90. HRMS calcd for $\mathrm{C}_{19} \mathrm{H}_{16} \mathrm{BrN}_{4}{ }^{+}[\mathrm{M}+\mathrm{H}]{ }^{+} 379.0553$, found 379.0547. HPLC purity $97.81 \%\left(\mathrm{t}_{\mathrm{R}}=14.7 \mathrm{~min}\right)$. 
3.1.52. 4-(5-Bromo- $1 H$-indol-3-yl)- $N$-(p-tolyl) pyrimidin-2-amine B15

Yield: $41 \%$, pale yellow solid, $\mathrm{mp} 227.8-228.6{ }^{\circ} \mathrm{C} .{ }^{1} \mathrm{H}$ NMR $\left(400 \mathrm{MHz}, \mathrm{DMSO}-d_{6}\right) \delta$ $12.06(\mathrm{~s}, 1 \mathrm{H}), 9.36(\mathrm{~s}, 1 \mathrm{H}), 8.74(\mathrm{~s}, 1 \mathrm{H}), 8.34(\mathrm{~d}, J=30.0 \mathrm{~Hz}, 2 \mathrm{H}), 7.71-7.59(\mathrm{~m}, 2 \mathrm{H}), 7.42(\mathrm{~s}$, $1 \mathrm{H}), 7.28(\mathrm{~d}, J=29.2 \mathrm{~Hz}, 2 \mathrm{H}), 7.21-7.11(\mathrm{~m}, 2 \mathrm{H}), 2.28(\mathrm{~s}, 3 \mathrm{H}){ }^{13} \mathrm{C}$ NMR $\left(100 \mathrm{MHz}\right.$, DMSO- $\left.d_{6}\right)$ $\delta 162.47,160.73,157.43,138.52,136.28,130.78,130.63,129.46,127.24,125.22,124.84,120.24$, $114.38,113.96,113.71,107.41,20.97$. HRMS calcd for $\mathrm{C}_{19} \mathrm{H}_{16} \mathrm{BrN}_{4}{ }^{+}[\mathrm{M}+\mathrm{H}]{ }^{+} 379.0553$, found 379.0552 . HPLC purity $96.65 \%\left(t_{R}=14.8 \mathrm{~min}\right)$.

\subsubsection{4-(5-Bromo-1H-indol-3-yl)-N-(2-methoxyphenyl) pyrimidin-2-amine B16}

Yield: $36 \%$, pale yellow solid, mp 207.9-208.3 ${ }^{\circ} \mathrm{C} .{ }^{1} \mathrm{H}$ NMR $\left(400 \mathrm{MHz}\right.$, DMSO- $\left.d_{6}\right)$ $\delta 11.97(\mathrm{~s}, 1 \mathrm{H}), 8.58(\mathrm{~s}, 1 \mathrm{H}), 8.36(\mathrm{~s}, 1 \mathrm{H}), 8.29(\mathrm{~d}, J=5.4 \mathrm{~Hz}, 1 \mathrm{H}), 8.10-8.05(\mathrm{~m}, 2 \mathrm{H})$, $7.40(\mathrm{~d}, J=8.5 \mathrm{~Hz}, 1 \mathrm{H}), 7.31-7.24(\mathrm{~m}, 2 \mathrm{H}), 7.12-6.98(\mathrm{~m}, 3 \mathrm{H}), 3.84(\mathrm{~s}, 3 \mathrm{H}) .{ }^{13} \mathrm{C}$ NMR $\left(100 \mathrm{MHz}, \mathrm{DMSO}-d_{6}\right) \delta 162.77,160.89,157.80,150.46,136.45,131.11,129.35,127.42,125.41$, $124.83,123.74,122.18,121.13,114.61,114.15,113.79,111.72,107.96,56.31$. HRMS calcd for $\mathrm{C}_{19} \mathrm{H}_{16} \mathrm{BrN}_{4} \mathrm{O}^{+}[\mathrm{M}+\mathrm{H}]{ }^{+} 395.0502$, found 395.0502. HPLC purity $98.24 \%\left(t_{\mathrm{R}}=15.0 \mathrm{~min}\right)$.

3.1.54. 4-(5-Bromo-1H-indol-3-yl)-N-(3-methoxyphenyl) pyrimidin-2-amine B17

Yield: $49 \%$, pale yellow solid, $\mathrm{mp} 208.7-209.3{ }^{\circ} \mathrm{C} .{ }^{1} \mathrm{H}$ NMR $\left(400 \mathrm{MHz}\right.$, DMSO- $\left.d_{6}\right) \delta$ $11.96(\mathrm{~s}, 1 \mathrm{H}), 9.44(\mathrm{~s}, 1 \mathrm{H}), 8.73(\mathrm{~s}, 1 \mathrm{H}), 8.34(\mathrm{~s}, 1 \mathrm{H}), 8.30(\mathrm{~d}, J=5.3 \mathrm{~Hz}, 1 \mathrm{H}), 7.39(\mathrm{~d}, J=8.7 \mathrm{~Hz}$, $3 \mathrm{H}), 7.27(\mathrm{~d}, J=8.6 \mathrm{~Hz}, 1 \mathrm{H}), 7.23(\mathrm{~d}, J=5.4 \mathrm{~Hz}, 1 \mathrm{H}), 7.19(\mathrm{t}, J=8.1 \mathrm{~Hz}, 1 \mathrm{H}), 6.51(\mathrm{~d}, J=8.0 \mathrm{~Hz}$, $1 \mathrm{H}), 3.68(\mathrm{~s}, 3 \mathrm{H}) .{ }^{13} \mathrm{C}$ NMR $\left(100 \mathrm{MHz}\right.$, DMSO- $\left.d_{6}\right) \delta 161.69,159.67,159.22,156.56,141.57$, $135.45,129.97,128.87,126.40,124.47,124.01,113.54,113.26,112.88,111.32,107.07,106.16$, 104.64, 54.45. HRMS calcd for $\mathrm{C}_{19} \mathrm{H}_{16} \mathrm{BrN}_{4} \mathrm{O}^{+}[\mathrm{M}+\mathrm{H}]{ }^{+} 395.0502$, found 395.0498. HPLC purity $97.43 \%\left(t_{R}=13.6 \mathrm{~min}\right)$.

\subsubsection{4-(5-Bromo-1H-indol-3-yl)- $\mathrm{N}$-(4-methoxyphenyl) pyrimidin-2-amine B18}

Yield: $47 \%$, pale yellow solid, mp $245.7-246.3{ }^{\circ} \mathrm{C} .{ }^{1} \mathrm{H}$ NMR $\left(400 \mathrm{MHz}\right.$, DMSO- $\left.d_{6}\right) \delta$ $11.96(\mathrm{~s}, 1 \mathrm{H}), 9.24(\mathrm{~s}, 1 \mathrm{H}), 8.72(\mathrm{~s}, 1 \mathrm{H}), 8.38(\mathrm{~d}, J=2.8 \mathrm{~Hz}, 1 \mathrm{H}), 8.30(\mathrm{~d}, J=5.3 \mathrm{~Hz}, 1 \mathrm{H}), 7.66$ $(\mathrm{d}, J=8.6 \mathrm{~Hz}, 2 \mathrm{H}), 7.44(\mathrm{~d}, J=8.5 \mathrm{~Hz}, 1 \mathrm{H}), 7.32(\mathrm{~d}, J=8.7 \mathrm{~Hz}, 1 \mathrm{H}), 7.23(\mathrm{~d}, J=5.3 \mathrm{~Hz}, 1 \mathrm{H})$, $6.96(\mathrm{~d}, J=8.6 \mathrm{~Hz}, 2 \mathrm{H}), 3.77(\mathrm{~s}, 3 \mathrm{H}) .{ }^{13} \mathrm{C}$ NMR $\left(100 \mathrm{MHz}, \mathrm{DMSO}-d_{6}\right) \delta 162.41,160.86,157.46$, $154.73,136.24,134.11,130.68,127.25,125.18,124.84,122.00,114.32,114.26,113.91,113.77$, 107.09, 55.60. HRMS calcd for $\mathrm{C}_{19} \mathrm{H}_{16} \mathrm{BrN}_{4} \mathrm{O}^{+}[\mathrm{M}+\mathrm{H}]+395.0502$, found 395.0497. HPLC purity $95.61 \%\left(t_{R}=13.4 \mathrm{~min}\right)$.

\subsubsection{4-(5-Bromo-1H-indol-3-yl)- $N$-(2-isopropylphenyl) pyrimidin-2-amine B19}

Yield: $41 \%$, pale yellow solid, mp $110.5-111.3{ }^{\circ} \mathrm{C} .{ }^{1} \mathrm{H}$ NMR $\left(400 \mathrm{MHz}\right.$, DMSO- $\left.d_{6}\right) \delta$ $11.88(\mathrm{~s}, 1 \mathrm{H}), 8.70(\mathrm{~d}, J=3.8 \mathrm{~Hz}, 1 \mathrm{H}), 8.29(\mathrm{~s}, 1 \mathrm{H}), 8.21(\mathrm{~d}, J=17.1 \mathrm{~Hz}, 2 \mathrm{H}), 7.41-7.30(\mathrm{~m}, 3 \mathrm{H})$, $7.29-7.20(\mathrm{~m}, 3 \mathrm{H}), 7.13(\mathrm{t}, J=4.6 \mathrm{~Hz}, 1 \mathrm{H}), 3.26(\mathrm{q}, J=6.4,5.7 \mathrm{~Hz}, 1 \mathrm{H}), 1.12(\mathrm{~d}, J=3.1 \mathrm{~Hz}$, $6 \mathrm{H}) .{ }^{13} \mathrm{C}$ NMR $\left(100 \mathrm{MHz}\right.$, DMSO- $\left.d_{6}\right) \delta 162.08,162.02,157.01,144.29,136.77,135.53,129.74$, $127.55,126.76,125.92,125.88,125.61,124.62,124.55,113.53,113.27,113.15,105.81,27.28$, 23.10. HRMS calcd for $\mathrm{C}_{21} \mathrm{H}_{20} \mathrm{BrN}_{4}{ }^{+}[\mathrm{M}+\mathrm{H}]{ }^{+} 407.0866$, found 407.0863. HPLC purity $98.51 \%\left(t_{R}=15.1 \mathrm{~min}\right)$.

\subsubsection{4-(5-Bromo-1H-indol-3-yl)- $N$-(3-isopropylphenyl) pyrimidin-2-amine B20}

Yield: $60 \%$, pale yellow solid, mp $152.6-153.4{ }^{\circ} \mathrm{C} .{ }^{1} \mathrm{H}$ NMR $\left(400 \mathrm{MHz}\right.$, DMSO- $\left.d_{6}\right) \delta$ $11.92(\mathrm{~s}, 1 \mathrm{H}), 9.33(\mathrm{~s}, 1 \mathrm{H}), 8.68(\mathrm{~d}, J=4.6 \mathrm{~Hz}, 1 \mathrm{H}), 8.32-8.23(\mathrm{~m}, 2 \mathrm{H}), 7.70(\mathrm{t}, J=6.1 \mathrm{~Hz}, 1 \mathrm{H})$, $7.45(\mathrm{~d}, J=4.6 \mathrm{~Hz}, 1 \mathrm{H}), 7.39-7.34(\mathrm{~m}, 1 \mathrm{H}), 7.25-7.15(\mathrm{~m}, 3 \mathrm{H}), 6.77(\mathrm{t}, J=6.2 \mathrm{~Hz}, 1 \mathrm{H}), 2.77(\mathrm{q}$, $J=6.8 \mathrm{~Hz}, 1 \mathrm{H}), 1.13(\mathrm{~d}, J=6.1 \mathrm{~Hz}, 6 \mathrm{H}) .{ }^{13} \mathrm{C}$ NMR $\left(100 \mathrm{MHz}, \mathrm{DMSO}-d_{6}\right) \delta 162.33,160.45$, 157.22, 148.95, 140.94, 136.11, 130.56, 128.71, 127.07, 125.11, 124.58, 119.58, 117.56, 117.19, 114.21, 113.86, 113.58, 107.54, 33.85, 24.25. HRMS calcd for $\mathrm{C}_{21} \mathrm{H}_{20} \mathrm{BrN}_{4}{ }^{+}[\mathrm{M}+\mathrm{H}]^{+} 407.0866$, found 407.0866 . HPLC purity $98.50 \%\left(t_{R}=15.8 \mathrm{~min}\right)$. 
3.1.58. 4-(5-Bromo-1H-indol-3-yl)-N-(4-isopropylphenyl) pyrimidin-2-amine B21

Yield: $41 \%$, pale yellow solid, $\mathrm{mp} 218.7-219.4{ }^{\circ} \mathrm{C} .{ }^{1} \mathrm{H}$ NMR $\left(400 \mathrm{MHz}, \mathrm{DMSO}-d_{6}\right) \delta$ $11.88(\mathrm{~s}, 1 \mathrm{H}), 9.26(\mathrm{~s}, 1 \mathrm{H}), 8.67(\mathrm{~s}, 1 \mathrm{H}), 8.27(\mathrm{~s}, 1 \mathrm{H}), 8.19(\mathrm{~d}, J=5.3 \mathrm{~Hz}, 1 \mathrm{H}), 7.56(\mathrm{~d}, J=8.2 \mathrm{~Hz}$, $2 \mathrm{H}), 7.33(\mathrm{~d}, J=8.6 \mathrm{~Hz}, 1 \mathrm{H}), 7.20(\mathrm{~d}, J=8.6 \mathrm{~Hz}, 1 \mathrm{H}), 7.15-7.10(\mathrm{~m}, 3 \mathrm{H}), 2.78-2.72(\mathrm{~m}, 1 \mathrm{H})$, $1.10(\mathrm{~d}, J=6.9 \mathrm{~Hz}, 6 \mathrm{H}) .{ }^{13} \mathrm{C}$ NMR $\left(100 \mathrm{MHz}, \mathrm{DMSO}-d_{6}\right) \delta 161.88,160.12,156.93,141.25$, $138.17,135.72,130.22,126.67,126.22,124.66,124.28,119.63,113.83,113.38,113.22,106.85$, 32.78, 23.99. HRMS calcd for $\mathrm{C}_{21} \mathrm{H}_{20} \mathrm{BrN}_{4}{ }^{+}[\mathrm{M}+\mathrm{H}]{ }^{+} 407.0866$, found 407.0870. HPLC purity $98.97 \%\left(t_{R}=16.3 \mathrm{~min}\right)$.

3.1.59. 4-(5-Bromo- $1 H$-indol-3-yl)- $N$-phenylpyrimidin-2-amine $\mathbf{B} 22$

Yield: $46 \%$, pale yellow solid, mp 197.6-198.7 ${ }^{\circ} \mathrm{C} .{ }^{1} \mathrm{H}$ NMR $\left(400 \mathrm{MHz}, \mathrm{DMSO}-d_{6}\right)$ $\delta 12.06(\mathrm{~s}, 1 \mathrm{H}), 9.46(\mathrm{~s}, 1 \mathrm{H}), 8.77(\mathrm{~s}, 1 \mathrm{H}), 8.37(\mathrm{~s}, 1 \mathrm{H}), 8.33(\mathrm{~d}, J=5.3 \mathrm{~Hz}, 1 \mathrm{H}), 7.79(\mathrm{~d}$, $J=8.0 \mathrm{~Hz}, 2 \mathrm{H}), 7.45(\mathrm{~d}, J=8.6 \mathrm{~Hz}, 1 \mathrm{H}), 7.33(\mathrm{q}, J=9.4,8.5 \mathrm{~Hz}, 3 \mathrm{H}), 7.27(\mathrm{~d}, J=5.3 \mathrm{~Hz}$, $1 \mathrm{H}), 6.98(\mathrm{t}, J=7.3 \mathrm{~Hz}, 1 \mathrm{H}) .{ }^{13} \mathrm{C}$ NMR $\left(100 \mathrm{MHz}, \mathrm{DMSO}-d_{6}\right) \delta 162.36,160.38,157.23,140.98$, 136.21, 130.81, 128.82, 127.06, 124.97, 124.55, 121.53, 119.60, 114.31, 113.78, 113.42, 107.56. HRMS calcd for $\mathrm{C}_{18} \mathrm{H}_{14} \mathrm{BrN}_{4}{ }^{+}[\mathrm{M}+\mathrm{H}]{ }^{+} 365.0396$, found 365.0397 . HPLC purity $98.81 \%$ $\left(\mathrm{t}_{\mathrm{R}}=10.5 \mathrm{~min}\right)$.

\subsubsection{4-(5-Bromo-1H-indol-3-yl)- $N$-(3,5-difluorophenyl) pyrimidin-2-amine B23}

Yield: 52\%, pale yellow solid, mp 251.3-252.2 ${ }^{\circ} \mathrm{C} .{ }^{1} \mathrm{H}$ NMR $\left(400 \mathrm{MHz}\right.$, DMSO- $\left.d_{6}\right) \delta$ $12.06(\mathrm{~s}, 1 \mathrm{H}), 9.92(\mathrm{~s}, 1 \mathrm{H}), 8.73(\mathrm{~d}, J=2.0 \mathrm{~Hz}, 1 \mathrm{H}), 8.52-8.24(\mathrm{~m}, 2 \mathrm{H}), 7.63-7.58(\mathrm{~m}, 2 \mathrm{H}), 7.46$ $(\mathrm{d}, J=8.6 \mathrm{~Hz}, 1 \mathrm{H}), 7.38(\mathrm{~d}, J=5.4 \mathrm{~Hz}, 1 \mathrm{H}), 7.35-7.32(\mathrm{~m}, 1 \mathrm{H}), 6.74(\mathrm{t}, J=9.3 \mathrm{~Hz}, 1 \mathrm{H}) .{ }^{13} \mathrm{C}$ NMR $\left(100 \mathrm{MHz}\right.$, DMSO- $\left.d_{6}\right) \delta 163.86(\mathrm{~d}, J=16.1 \mathrm{~Hz}), 162.34,161.47(\mathrm{~d}, J=16.0 \mathrm{~Hz}), 159.54$, $156.97,143.53(\mathrm{~d}, J=14.6 \mathrm{~Hz}), 135.92,130.73,126.78,125.01,124.17,114.10,113.79,113.02$, 108.62, $101.42(\mathrm{~d}, J=8.1 \mathrm{~Hz})$. HRMS calcd for $\mathrm{C}_{18} \mathrm{H}_{12} \mathrm{BrF}_{2} \mathrm{~N}_{4}{ }^{+}[\mathrm{M}+\mathrm{H}]^{+} 401.0208$, found 401.0201 HPLC purity $96.39 \%\left(t_{R}=14.7 \mathrm{~min}\right)$.

\subsubsection{4-(5-Bromo-1H-indol-3-yl)- $N$-(3,5-dichlorophenyl) pyrimidin-2-amine B24}

Yield: $63 \%$, pale yellow solid, mp 223.6-224.3 ${ }^{\circ} \mathrm{C} .{ }^{1} \mathrm{H}$ NMR $\left(400 \mathrm{MHz}, \mathrm{DMSO}-d_{6}\right) \delta$ $12.02(\mathrm{~s}, 1 \mathrm{H}), 9.84(\mathrm{~s}, 1 \mathrm{H}), 8.66(\mathrm{~d}, J=2.0 \mathrm{~Hz}, 1 \mathrm{H}), 8.39(\mathrm{~s}, 1 \mathrm{H}), 8.37(\mathrm{~d}, J=3.0 \mathrm{~Hz}, 1 \mathrm{H})$, $7.91(\mathrm{~d}, J=1.9 \mathrm{~Hz}, 2 \mathrm{H}), 7.41(\mathrm{~d}, J=8.6 \mathrm{~Hz}, 1 \mathrm{H}), 7.34(\mathrm{~d}, J=5.4 \mathrm{~Hz}, 1 \mathrm{H}), 7.31-7.27(\mathrm{~m}, 1 \mathrm{H})$, $7.06(\mathrm{t}, J=1.8 \mathrm{~Hz}, 1 \mathrm{H}) .{ }^{13} \mathrm{C}$ NMR $\left(100 \mathrm{MHz}, \mathrm{DMSO}-d_{6}\right) \delta 162.82,159.84,157.34,143.86$, $136.33,134.40,131.13,127.23,125.49,124.60,120.30,117.01,114.50,114.27,113.39,109.14$. HRMS calcd for $\mathrm{C}_{18} \mathrm{H}_{12} \mathrm{BrCl}_{2} \mathrm{~N}_{4}{ }^{+}[\mathrm{M}+\mathrm{H}]{ }^{+} 432.9617$, found 432. 9611. HPLC purity $97.08 \%$ $\left(\mathrm{t}_{\mathrm{R}}=16.7 \mathrm{~min}\right)$.

\subsubsection{4-(5-Bromo-1H-indol-3-yl)- $N$-(3,5-dibromophenyl) pyrimidin-2-amine B25}

Yield: $48 \%$, pale yellow solid, mp 193.4-193.7 ${ }^{\circ} \mathrm{C} .{ }^{1} \mathrm{H}$ NMR $\left(400 \mathrm{MHz}\right.$, DMSO- $\left.d_{6}\right) \delta$ $11.91(\mathrm{~s}, 1 \mathrm{H}), 9.68(\mathrm{~s}, 1 \mathrm{H}), 8.54(\mathrm{~s}, 1 \mathrm{H}), 8.29-8.23(\mathrm{~m}, 2 \mathrm{H}), 7.98-7.94(\mathrm{~m}, 2 \mathrm{H}), 7.30(\mathrm{~d}, J=8.5 \mathrm{~Hz}$, $1 \mathrm{H}), 7.21(\mathrm{~d}, J=5.4 \mathrm{~Hz}, 1 \mathrm{H}), 7.18(\mathrm{~d}, J=4.9 \mathrm{~Hz}, 2 \mathrm{H}) .{ }^{13} \mathrm{C}$ NMR $\left(100 \mathrm{MHz}, \mathrm{DMSO}-d_{6}\right) \delta$ $162.28,159.25,156.82,143.68,135.80,130.53,126.69,125.08,125.00,124.09,122.23,119.67$, 113.99, 113.79, 112.85, 108.61. HRMS calcd for $\mathrm{C}_{18} \mathrm{H}_{14} \mathrm{Br}_{3} \mathrm{~N}_{4}{ }^{+}[\mathrm{M}+\mathrm{H}]{ }^{+} 522.8763$, found 522.8587. HPLC purity $97.05 \%\left(t_{R}=17.3 \mathrm{~min}\right)$.

3.1.63. N-(3,5-bis(trifluoromethyl)phenyl)-4-(5-bromo-1H-indol-3-yl) pyrimidin-2-amine B26

Yield: 59\%, pale yellow solid, mp $220.9-221.3{ }^{\circ} \mathrm{C} .{ }^{1} \mathrm{H}$ NMR $\left(400 \mathrm{MHz}\right.$, DMSO- $\left.d_{6}\right) \delta$ $12.06(\mathrm{~s}, 1 \mathrm{H}), 10.17(\mathrm{~s}, 1 \mathrm{H}), 8.68(\mathrm{~s}, 1 \mathrm{H}), 8.55(\mathrm{~s}, 2 \mathrm{H}), 8.45(\mathrm{~d}, J=5.4 \mathrm{~Hz}, 1 \mathrm{H}), 8.40(\mathrm{~s}, 1 \mathrm{H})$, $7.56(\mathrm{~s}, 1 \mathrm{H}), 7.42(\mathrm{t}, J=7.8 \mathrm{~Hz}, 2 \mathrm{H}), 7.31(\mathrm{~d}, J=7.6 \mathrm{~Hz}, 1 \mathrm{H}) .{ }^{13} \mathrm{C}$ NMR $\left(100 \mathrm{MHz}, \mathrm{DMSO}-d_{6}\right)$ $\delta$ 162.54, 159.37, 156.90, 142.96, 135.93, $130.93(\mathrm{~d}, J=34.2 \mathrm{~Hz}), 130.30(\mathrm{~d}, J=32.3 \mathrm{~Hz})$, $126.79,125.08,124.94(\mathrm{q}, J=273.7 \mathrm{~Hz}), 124.12,118.04,114.09,113.84,113.17,112.88,109.08$. HRMS calcd for $\mathrm{C}_{20} \mathrm{H}_{12} \mathrm{BrF}_{6} \mathrm{~N}_{4}{ }^{+},[\mathrm{M}+\mathrm{H}]{ }^{+} 501.0144$, found 501.0138. HPLC purity $97.89 \%$ $\left(t_{R}=16.1 \mathrm{~min}\right)$. 
3.1.64. 4-(5-Bromo- $1 H$-indol-3-yl)- $N$-(3, 5-dimethylphenyl) pyrimidin-2-amine B27

Yield: $42 \%$, pale yellow solid, mp $184.6-185.3{ }^{\circ} \mathrm{C} .{ }^{1} \mathrm{H}$ NMR $\left(400 \mathrm{MHz}, \mathrm{DMSO}-d_{6}\right)$ $\delta 11.94(\mathrm{~s}, 1 \mathrm{H}), 9.29(\mathrm{~s}, 1 \mathrm{H}), 8.66(\mathrm{~s}, 1 \mathrm{H}), 8.30(\mathrm{~d}, J=16.5 \mathrm{~Hz}, 2 \mathrm{H}), 7.38(\mathrm{~s}, 3 \mathrm{H}), 7.23(\mathrm{~d}$, $J=30.4 \mathrm{~Hz}, 2 \mathrm{H}), 6.55(\mathrm{~s}, 1 \mathrm{H}), 2.21(\mathrm{~s}, 6 \mathrm{H}) .{ }^{13} \mathrm{C}$ NMR $\left(100 \mathrm{MHz}, \mathrm{DMSO}-d_{6}\right) \delta 161.84,159.96$, $156.81,140.44,137.19,135.67,130.06,126.70,124.71,124.15,122.78,116.73,113.77,113.37$, 113.20, 107.03, 21.21. HRMS calcd for $\mathrm{C}_{20} \mathrm{H}_{18} \mathrm{BrN}_{4}{ }^{+}[\mathrm{M}+\mathrm{H}]{ }^{+} 393.0709$, found 393.0712 HPLC purity $97.05 \%\left(t_{R}=15.3 \mathrm{~min}\right)$.

3.1.65. 4-(5-Bromo- $1 H$-indol-3-yl)- $N$-(3, 5-dimethoxyphenyl) pyrimidin-2-amine B28

Yield: $48 \%$, pale yellow solid, $\mathrm{mp} 255.6-256.8{ }^{\circ} \mathrm{C} .{ }^{1} \mathrm{H}$ NMR $\left(400 \mathrm{MHz}, \mathrm{DMSO}-d_{6}\right) \delta$ $11.96(\mathrm{~s}, 1 \mathrm{H}), 9.40(\mathrm{~s}, 1 \mathrm{H}), 8.71(\mathrm{~s}, 1 \mathrm{H}), 8.33(\mathrm{~d}, J=2.5 \mathrm{~Hz}, 1 \mathrm{H}), 8.30(\mathrm{~d}, J=5.3 \mathrm{~Hz}, 1 \mathrm{H})$, $7.39(\mathrm{~d}, J=8.6 \mathrm{~Hz}, 1 \mathrm{H}), 7.29-7.25(\mathrm{~m}, 1 \mathrm{H}), 7.23(\mathrm{~d}, J=5.4 \mathrm{~Hz}, 1 \mathrm{H}), 7.04(\mathrm{~d}, J=2.2 \mathrm{~Hz}, 2 \mathrm{H})$, $6.09(\mathrm{~s}, 1 \mathrm{H}), 3.67(\mathrm{~s}, 6 \mathrm{H}) .{ }^{13} \mathrm{C}$ NMR $\left(100 \mathrm{MHz}, \mathrm{DMSO}-d_{6}\right) \delta 162.53,160.96,160.46,157.37$, $142.89,136.29,130.76,127.25,125.37,124.87,114.39,114.16,113.70,108.04,97.92,93.74,55.40$. HRMS calcd for $\mathrm{C}_{20} \mathrm{H}_{18} \mathrm{BrN}_{4} \mathrm{O}_{2}{ }^{+}[\mathrm{M}+\mathrm{H}]{ }^{+} 425.0608$, found 425.0601 . HPLC purity $96.76 \%$ $\left(t_{R}=13.3 \mathrm{~min}\right)$.

3.1.66. 4-(5-Bromo-1H-indol-3-yl)- $N$-(2,6-difluorophenyl) pyrimidin-2-amine B29

Yield: 40\%, pale yellow solid, $\mathrm{mp} 263.3-264.2{ }^{\circ} \mathrm{C} .{ }^{1} \mathrm{H}$ NMR $\left(400 \mathrm{MHz}, \mathrm{DMSO}-d_{6}\right) \delta$ $11.87(\mathrm{~s}, 1 \mathrm{H}), 8.91(\mathrm{~s}, 1 \mathrm{H}), 8.23(\mathrm{~d}, J=40.8 \mathrm{~Hz}, 3 \mathrm{H}), 7.53-7.01(\mathrm{~m}, 7 \mathrm{H}) .{ }^{13} \mathrm{C} \mathrm{NMR}(100 \mathrm{MHz}$, DMSO- $\left.d_{6}\right) \delta 162.85,161.48,160.29(\mathrm{~d}, J=5.2 \mathrm{~Hz}), 157.83(\mathrm{~d}, J=5.1 \mathrm{~Hz}), 157.57,136.15,130.69$, 127.36, 125.23, 124.72, 114.23, 113.91, 113.41, $112.50(\mathrm{~d}, J=5.9 \mathrm{~Hz}), 112.32(\mathrm{~d}, J=5.2 \mathrm{~Hz})$, 107.43. HRMS calcd for $\mathrm{C}_{18} \mathrm{H}_{12} \mathrm{BrF}_{2} \mathrm{~N}_{4}{ }^{+},[\mathrm{M}+\mathrm{H}]{ }^{+} 401.0208$, found 401.0201. HPLC purity $97.49 \%\left(t_{R}=12.4 \mathrm{~min}\right)$.

\subsubsection{4-(5-Bromo-1H-indol-3-yl)- $N$-(2,6-dimethylphenyl) pyrimidin-2-amine B30}

Yield: $34 \%$, pale yellow solid, $\mathrm{mp} 228.5-229.4{ }^{\circ} \mathrm{C} .{ }^{1} \mathrm{H}$ NMR $\left(400 \mathrm{MHz}, \mathrm{DMSO}-d_{6}\right) \delta$ $11.85(\mathrm{~s}, 1 \mathrm{H}), 8.54(\mathrm{~s}, 1 \mathrm{H}), 8.24(\mathrm{~d}, J=38.1 \mathrm{~Hz}, 2 \mathrm{H}), 7.82(\mathrm{~s}, 1 \mathrm{H}), 7.33(\mathrm{~s}, 1 \mathrm{H}), 7.25-6.98(\mathrm{~m}$, $5 \mathrm{H}), 2.20(\mathrm{~s}, 6 \mathrm{H}) .{ }^{13} \mathrm{C}$ NMR $\left(100 \mathrm{MHz}\right.$, DMSO- $\left.d_{6}\right) \delta 162.27,161.60,157.27,148.03,137.14$, $135.62,129.80,128.05,126.99,126.08,124.73,124.44,113.64,113.40,113.32,105.52,18.58$. HRMS calcd for $\mathrm{C}_{20} \mathrm{H}_{18} \mathrm{BrN}_{4}{ }^{+}[\mathrm{M}+\mathrm{H}]{ }^{+} 393.0709$, found 393.0715 . HPLC purity $96.56 \%$ $\left(\mathrm{t}_{\mathrm{R}}=14.2 \mathrm{~min}\right)$.

3.1.68. 4-(5-Bromo-1H-indol-3-yl)-N-(2,6-dimethoxyphenyl) pyrimidin-2-amine B31

Yield: $62 \%$, pale yellow solid, mp 244.3-245.6 ${ }^{\circ} \mathrm{C} .{ }^{1} \mathrm{H}$ NMR $\left(400 \mathrm{MHz}, \mathrm{DMSO}-d_{6}\right) \delta$ $11.74(\mathrm{~s}, 1 \mathrm{H}), 8.15(\mathrm{~s}, 1 \mathrm{H}), 8.01(\mathrm{~d}, J=5.3 \mathrm{~Hz}, 1 \mathrm{H}), 7.92(\mathrm{~s}, 1 \mathrm{H}), 7.25(\mathrm{~d}, J=8.5 \mathrm{~Hz}, 1 \mathrm{H})$, 7.15-7.09 (m, 2H), $6.95(\mathrm{~d}, J=5.3 \mathrm{~Hz}, 1 \mathrm{H}), 6.65(\mathrm{~d}, J=8.4 \mathrm{~Hz}, 2 \mathrm{H}), 3.60(\mathrm{~s}, 6 \mathrm{H}) .{ }^{13} \mathrm{C}$ NMR $\left(100 \mathrm{MHz}\right.$, DMSO- $\left.d_{6}\right) \delta 162.50,162.37,157.25,156.70,136.12,130.09,127.49,127.38,125.20$, $125.04,117.15,114.14,113.93,113.82,106.08,105.16,56.00$. HRMS calcd for $\mathrm{C}_{20} \mathrm{H}_{18} \mathrm{BrN}_{4} \mathrm{O}_{2}{ }^{+}$ $[\mathrm{M}+\mathrm{H}]^{+} 425.0608$, found 425.0600 . HPLC purity $97.85 \%\left(\mathrm{t}_{\mathrm{R}}=12.2 \mathrm{~min}\right)$.

\subsection{Biological Evaluation}

\subsubsection{General Procedure}

The hepatocyte cell line HepG2 cells obtained from the Type Culture Collection of the Chinese Academy of Sciences (Shanghai, China) were maintained in high-glucose DMEM (Gibco) supplemented with 10\% fetal bovine serum (FBS) and 1\% penicillin-streptomycin in an atmosphere of $5 \% \mathrm{CO}_{2}$ at $37^{\circ} \mathrm{C}$.

\subsubsection{MTT Assay for Cell Viability}

Into a 96-well plate, $1 \times 10^{3} \mathrm{HepG} 2$ cells per well were seeded. After $24 \mathrm{~h}$, stock solutions of test compounds in DMSO were diluted in DMEM to $\leq 0.1 \%$ final DMSO concentration. Cells were treated with various concentrations $(2.5-25 \mu \mathrm{M})$ of tested compounds for $48 \mathrm{~h}$, and the MTT solution $(0.5 \mathrm{mg} / \mathrm{mL})$ was added. After $4 \mathrm{~h}$ of incubation at $37^{\circ} \mathrm{C}$ for MTT-formazan formation, the supernatant was discarded and $100 \mu \mathrm{L}$ of DMSO was 
applied into each well to dissolve formazan crystals. Absorbance at $490 \mathrm{~nm}$ was determined spectrophotometrically by using a microplate reader (Epoch, BioTek Instruments, Inc., Winooski, VT, USA).

\subsubsection{Inhibition of GSK-3 $\beta$}

The activity of recombinant GSK-3 $\beta$ (Invitrogen) was measured in a Z-lyte assay of Invitrogen. In this assay, $100 \mathrm{~nL}$ of the compound solution in DMSO was transferred to a 384-well assay plate (the compound got threefold serial dilution, and the top concentration of the compound was $30 \mu \mathrm{M}$ in the final reaction mixture). Then $5 \mu \mathrm{L}$ of an enzyme $(2 \mathrm{nM})$ and Ser $/ \mathrm{Thr} 9$ peptide $(4 \mu \mathrm{M})$ mixture was added. After the enzyme and peptide pre-incubation with the compound for $30 \mathrm{~min}$ at $23{ }^{\circ} \mathrm{C}, 5 \mu \mathrm{L}$ of ATP $(12 \mu \mathrm{M})$ solution was added. The plate was incubated for $60 \mathrm{~min}$ at $23^{\circ} \mathrm{C}$. The reaction was stopped with $5 \mu \mathrm{L}$ of development reagent. Fluorescence signals were detected with Envision (PerkinElmer, America) after $30 \mathrm{~min}$ of incubation, and the emission ratio (RFU $460 \mathrm{~nm} / \mathrm{RFU} 535 \mathrm{~nm}$ ) was used to analyze the data. The relative $\mathrm{IC}_{50}$ was reported using four-parameter logistic fit of IDBS Xlfit software. The $\mathrm{IC}_{50}$ values were calculated using the following equation:

$$
\% \text { Phosphorylation }=1-\frac{\left(\text { Emission Ratio } \times \mathrm{F}_{100 \%}\right)-\mathrm{C}_{100 \%}}{\left(\mathrm{C}_{0 \%}-\mathrm{C}_{100 \%}\right)+\left[\text { Emission Ratio } \times\left(\mathrm{F}_{100 \%}-\mathrm{F}_{0 \%}\right)\right]}
$$

where

Emission ratio $=$ Coumarin $/$ Fluorescein ratio of sample wells

$\mathrm{C}_{100 \%}=$ Average coumarin emission signal of the $100 \%$ phos. control

$\mathrm{C}_{0} \%=$ Average coumarin emission signal of the $0 \%$ phos. control

$\mathrm{F}_{100 \%}=$ Average fluorescein emission signal of the $100 \%$ phos. control

$\mathrm{F}_{0 \%}=$ Average fluorescein emission signal of the $0 \%$ phos. control

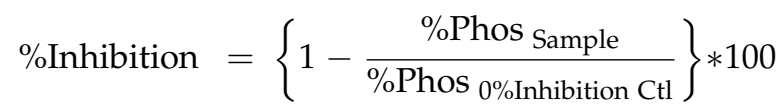

\subsubsection{Cell Glucose Uptake Assay}

Into a 96-well plate, $5 \times 10^{3} \mathrm{HepG} 2$ cells per well were seeded. After $48 \mathrm{~h}$, phenol red-free DMEM (Gibco) with 1\% FBS was transferred to deprive the cells overnight, and then the tested compounds dissolved in a glucose-HEPES buffer (glucose concentration was $100 \mu \mathrm{g} / \mathrm{mL}$ ) at a concentration of $5 \mu \mathrm{M}$ were added to the culture system. Three hours later, the culture supernatants were collected and the glucose concentrations were detected using the Glucose (GO) Assay Kit (Sigma-Aldrich Corp.). Compared with the original glucose concentration of the buffer, the relative glucose uptake was calculated.

\subsubsection{Assay Molecular Modeling}

The modeling study was carried out using Schrödinger Maestro 11.4. GSK-3 $\beta$ protein models (PDB entry 6B8J) were minimized by Schrödinger BioLuminate. The docking study was performed using Glide. The parameters chosen were the default ones, without any constraints. The molecular docking result was generated using PyMol (http://pymol. sourceforge.net/ accessed on 10 January 2021).

\section{Conclusions}

In summary, a series of 2-aminopyrimidine- and 5-aminophenyl-modified marineoriginated meridianin $C$ analogues were designed and synthesized by a structural-based optimization strategy. Among the analogues, B29 and B30 with 2-aminopyrimidine substitutions could significantly increase hepatocyte glucose uptake in HepG2 cells, with good inhibitory activity against GSK-3 $\beta$, showing potential for the treatment of diabetes. They represent potential lead compounds for further development of GSK-3 $\beta$ and antidiabetic drugs. 
Supplementary Materials: The following are available online at https:/ /www.mdpi.com/1660-339 7/19/3/149/s1: NMR, HRMS, HPLC purity.

Author Contributions: F.C. and W.Z. conceived and designed the experiments; S.H. and W.Z. performed the experiments. S.H. and W.Z. collected and analyzed the data; S.H., C.Z., and F.C. wrote the paper. All authors have read and agreed to the published version of the manuscript.

Funding: This work was financially supported by the National Natural Science Foundation of China (22077018) and Fudan University (JIH1615060).

Acknowledgments: We thank Ningxia Medical University for providing us the computational sources. This work was supported by National Key R\&D Program of China (2017YFA0506000).

Conflicts of Interest: The authors declare no conflict of interest.

\begin{abstract}
Abbreviations
GSK-3 $\beta$, glycogen synthase kinase $3 \beta$; GCS, glycogen synthase; HepG2, human hepatocellular carcinoma; FBS, fetal bovine serum; PBS, phosphate buffered saline; HPLC, high-performance liquid chromatography; NMR, nuclear magnetic resonance; DMF, dimethylformamide; DMAP, 4(dimethylamino)-pyridine; DIPEA, N,N-diisopropylethylamine; NIS, N-iodosuccinimide; TsCl, tosyl chloride; ADMET, (absorption, distribution, metabolism, excretion, and toxicity); TDZD-8, 4-benzyl2-methyl-1,2,4-thiadiazolidine-3,5-dione.
\end{abstract}

\title{
References
}

1. Disbetes. Available online: https://www.who.int/health-topics/diabetes (accessed on 18 January 2021).

2. Karuranga, S.; Malanda, B.; Saeedi, P.; Salpea, P. IDF Diabetes Atlas, 9th ed.; International Diabetes Foundation: Brussels, Belgium, 2019; pp. 1-168.

3. Gangopadhyay, K.; Singh, P. Consensus statement on dose modifications of antidiabetic agents in patients with hepatic impairment. Indian J. Endocr. Metab. 2017, 21, 341-354. [CrossRef] [PubMed]

4. Padhi, S.; Nayak, A.K.; Behera, A. Type II diabetes mellitus: A review on recent drug based therapeutics. Biomed. Pharmacother. 2020, 131, 110708-111100. [CrossRef]

5. Feingold, K.R.; Anawalt, B.; Boyce, A. (Eds.) Oral and Injectable (Non-Insulin) Pharmacological Agents for Type 2 Diabetes; MDText. com, Inc.: South Dartmouth, MA, USA, 2000.

6. $\quad$ Palomo, V.; Perez, D.I.; Roca, C.; Anderson, C.; Rodriguez-Muela, N.; Perez, C.; Morales-Garcia, J.A.; Reyes, J.A.; Campillo, N.E.; Perez-Castillo, A.M.; et al. Subtly Modulating Glycogen Synthase Kinase 3 beta: Allosteric Inhibitor Development and Their Potential for the Treatment of Chronic Diseases. J. Med. Chem. 2017, 60, 4983-5001. [CrossRef]

7. Skropeta, D.; Pastro, N.; Zivanovic, A. Kinase inhibitors from marine sponges. Mar. Drugs 2011, 9, 2131-2154. [CrossRef]

8. Bharate, S.B.; Sawant, S.D.; Singh, P.P.; Vishwakarma, R.A. Kinase inhibitors of marine origin. Chem. Rev. 2013, 113, 6761-6815. [CrossRef] [PubMed]

9. Vadivelan, S.; Sinha, B.N.; Tajne, S.; Jagarlapudi, S.A. Fragment and knowledge-based design of selective GSK-3beta inhibitors using virtual screening models. Eur. J. Med. Chem. 2009, 44, 2361-2371. [CrossRef]

10. Park, H.; Shin, Y.; Kim, J.; Hong, S. Application of Fragment-Based de Novo Design to the Discovery of Selective Picomolar Inhibitors of Glycogen Synthase Kinase-3 Beta. J. Med. Chem. 2016, 59, 9018-9034. [CrossRef] [PubMed]

11. Tavares, F.X.; Boucheron, J.A.; Dickerson, S.H.; Griffin, R.J.; Preugschat, F.; Thomson, S.A.; Wang, T.Y.; Zhou, H.Q. N-Phenyl-4pyrazolo[1,5-b]pyridazin-3-ylpyrimidin-2-amines as potent and selective inhibitors of glycogen synthase kinase 3 with good cellular efficacy. J.Med. Chem. 2004, 47, 4716-4730. [CrossRef] [PubMed]

12. Wagman, A.S.; Boyce, R.S.; Brown, S.P.; Fang, E.; Goff, D.; Jansen, J.M.; Le, V.P.; Levine, B.H.; Ng, S.C.; Ni, Z.J.; et al. Synthesis, Binding Mode, and Antihyperglycemic Activity of Potent and Selective (5-Imidazol-2-yl-4-phenylpyrimidin-2-yl)[2-(2pyridylamino)ethyl]amine Inhibitors of Glycogen Synthase Kinase 3. J. Med. Chem. 2017, 60, 8482-8514. [CrossRef] [PubMed]

13. Zhang, W.Q.; Zhao, T.T.; Gui, D.K.; Gao, C.L.; Gu, J.L.; Gan, W.J.; Huang, W.; Xu, Y.; Zhou, H.; Chen, W.N.; et al. Sodium Butyrate Improves Liver Glycogen Metabolism in Type 2 Diabetes Mellitus. J. Agric. Food. Chem. 2019, 67, 7694-7705. [CrossRef] [PubMed]

14. Cline, G.W.; Johnson, K.; Regittnig, W.; Perret, P.; Tozzo, E.; Xiao, L.; Damico, C.; Shulman, G.I. Effects of a novel glycogen synthase kinase-3 inhibitor on insulin-stimulated glucose metabolism in Zucker diabetic fatty (fa/fa) rats. Diabetes 2002, 51, 2903-2910. [CrossRef] [PubMed]

15. Khan, I.; Tantray, M.A.; Alam, M.S.; Hamid, H. Natural and synthetic bioactive inhibitors of glycogen synthase kinase. Eur. J. Med. Chem. 2017, 125, 464-477. [CrossRef] [PubMed]

16. Walz, A.; Ugolkov, A.; Chandra, S.; Kozikowski, A.; Carneiro, B.A.; Halloran, T.V.; Giles, F.J.; Billadeau, D.D.; Mazar, A.P. Molecular Pathways: Revisiting Glycogen Synthase Kinase-3 $\beta$ as a Target for the Treatment of Cancer. Clin. Cancer Res. 2017, 23, 1891-1897. [CrossRef] [PubMed] 
17. Seldes, A.M.; Rodriguez Brasco, M.F.; Hernandez Franco, L.; Palermo, J.A. Identification of two meridianins from the crude extract of the tunicate Aplidium meridianum by tandem mass spectrometry. Nat. Prod. Res. 2007, 21, 555-563. [CrossRef] [PubMed]

18. Gompel, M.; Leost, M.; De Kier Joffe, E.B.; Puricelli, L.; Franco, L.H.; Palermo, J.; Meijer, L. Meridianins, a new family of protein kinase inhibitors isolated from the ascidian Aplidium meridianum. Bioorg. Med. Chem. Lett. 2004, 14, 1703-1707. [CrossRef] [PubMed]

19. Bharate, S.B.; Yadav, R.R.; Battula, S.; Vishwakarma, R.A. Meridianins: Marine-derived potent kinase inhibitors. Mini Rev. Med. Chem. 2012, 12, 618-631. [CrossRef] [PubMed]

20. Bharate, S.B.; Yadav, R.R.; Khan, S.I.; Tekwani, B.L.; Jacob, M.R.; Khan, I.A.; Vishwakarma, R.A. Meridianin G and its analogs as antimalarial agents. Med. Chem. Commun. 2013, 4, 1042-1048. [CrossRef]

21. Zhang, P.; Li, S.; Gao, Y.; Lu, W.; Huang, K.; Ye, D.; Li, X.; Chu, Y. Novel benzothiazinones (BTOs) as allosteric modulator or substrate competitive inhibitor of glycogen synthase kinase $3 \beta$ (GSK-3 $\beta$ ) with cellular activity of promoting glucose uptake. Bioorg. Med. Chem. Lett. 2014, 24, 5639-5643. [CrossRef] [PubMed] 